EMBRYARIDDLE
Aeronautical University

SCHOLARLY COMMONS
International Journal of Aviation, Aeronautics, and Aerospace

7-4-2016

\title{
A Model of Human Harm from a Falling Unmanned Aircraft: Implications for UAS Regulation
}

\author{
Andrew V. Shelley \\ Aviation Safety Management Systems Ltd, Andrew Shelley Economic Consulting Ltd, \\ andrew@asms.co.nz
}

Follow this and additional works at: https://commons.erau.edu/ijaaa

Part of the Aviation Safety and Security Commons, Law and Economics Commons, and the Risk Analysis Commons

\section{Scholarly Commons Citation}

Shelley, A. V. (2016). A Model of Human Harm from a Falling Unmanned Aircraft: Implications for UAS Regulation. International Journal of Aviation, Aeronautics, and Aerospace, 3(3). https://doi.org/10.15394/ ijaaa. 2016.1120

This Article is brought to you for free and open access by the Journals at Scholarly Commons. It has been accepted for inclusion in International Journal of Aviation, Aeronautics, and Aerospace by an authorized administrator of Scholarly Commons. For more information, please contact commons@erau.edu. 


\section{A Model of Human Harm from a Falling Unmanned Aircraft: Implications for UAS Regulation}

\section{Cover Page Footnote}

This article is derived from material to form a Masters Degree in the School of Economics and Finance, Victoria University of Wellington, supervised by Prof Lewis Evans. Thanks to Prof Evans, Nicola McCloy, and two anonymous reviewers for helpful comments. All errors are those of the author. Address for correspondence: Andrew.Shelley@xtra.co.nz. 
Aviation regulatory authorities are grappling with the problem posed by balancing the benefits of small Unmanned Aerial Systems (sUAS) with the safety risks posed to people on board manned aircraft and on the ground. They are proposing and implementing a range of solutions for the safety of people on the ground. For example, in 2015 the New Zealand Civil Aviation Authority (CAA) amended its Civil Aviation Rules (CAR) governing unmanned aircraft to prohibit operation in airspace above any person who has not given consent [CAR 101.207(a)(1)]. The Federal Aviation Administration (FAA) has chartered two committees to consider various aspects of sUAS regulation. In November 2015, the "Unmanned Aircraft Systems Registration Task Force Aviation Rulemaking Committee" (UAS Task Force) recommended that unmanned aircraft weighing $250 \mathrm{~g}$ or less should not require registration (UAS Task Force, 2015), and the FAA followed suit with similar requirements. More recently, in April 2016, the "Micro Unmanned Aircraft Systems Aviation Rulemaking Committee" (Micro UAS ARC) proposed four categories of UAS, with those unmanned aircraft weighing $250 \mathrm{~g}$ or less being able to operate without restriction over people (Micro UAS ARC, 2016).

Despite the rulemaking effort, and consultation that supports the rule making, there is little published analysis that supports the various existing and proposed rules. Dalamagkidis et al. (2008) calculate the required mean time between ground impacts for the fatality risk from unmanned aircraft to meet current aviation safety levels; this analysis is performed for the United States and for Greece. Ball et al. (2012) provide an analysis of the likely "lethal crash area" for various military unmanned aircraft; a significant part of their analysis concerns the harm caused by fire and explosion from liquid fuels in addition to kinetic energy harm. The Civil Aviation Safety Authority (CASA) in Australia has published a detailed analysis of human injuries resulting from small unmanned aircraft impacts (CASA, 2013); this analysis supports Australia's requirement that unmanned aircraft are not operated within 30m of a person who is not directly connected with the operation (Civil Aviation Safety Regulations 1998, rule 101.245(1)). There are limited calculations in the reports of the UAS Task Force (2015) and Micro UAS ARC (2016), but the analysis is somewhat perfunctory when compared to CASA (2013) and Ball et al. (2012). Skobir and Magister (2011) calculate the conditions under which the kinetic energy of impact from a fixed wing unmanned aircraft is equal to the kinetic energy of different classes of manned aircraft.

The limited quantity of available analysis, and the limited nature of some of that analysis, makes it difficult to judge whether the various rules overstate or understate the risks posed by sUAS. This paper is a contribution to expanding that body of analysis. Ideally, a cost-benefit analysis would be applied to determine the optimal trade-off between safety restrictions and the benefits provided by sUAS; however, as with most policy problems, the explicit quantification of benefits and 
costs is difficult to achieve. An alternative approach is adopted here; that of establishing a safety goal expressed as a social cost threshold and determining the least restrictive regulation that is consistent with that safety goal. Essentially, this is a least-cost analysis, which is consistent with the law and economic literature on safety regulation.

The literature review commences by reviewing examples of injuries and fatalities to establish that the type of harm considered in this analysis is more than just conjecture. The appropriate safety goal is then considered. Key points from the law and economic literature on the optimal level of safety are touched on, but ultimately a lack of information hinders our ability to determine what this optimal level might be. Instead, regulators are left in the position of establishing a safety goal that is "acceptable." The fatality rate for General Aviation is proposed as an appropriate safety goal for the present analysis.

Section 3 develops a model to quantify the human harm that could arise from an unmanned aircraft that strikes someone on the ground. To provide a level of comparison for different levels of harm, each outcome predicted by the model is valued using estimates of social cost normalized to the social cost of a fatality. The various formulae underlying the model are presented and the parameter estimates are discussed.

Section 4 presents the results from the modelling in the form of estimates of the maximum height above ground at which an unmanned aircraft can operate without violating the safety goal. Various population densities are considered, including densities representative of crowds at a public event. The effect of parachutes and the reliability of the aircraft is explored. The results of the analysis are then contrasted with the various existing and proposed regulatory rules discussed above. Section 5 provides concluding comments. Section 6 provides some brief observations on areas for further development of the model framework.

\section{Literature Review}

\section{Examples of Injuries and Fatalities}

In May 2015 an unmanned aircraft flying above a crowd at a Memorial Day parade in Marblehead, MA hit a building and crashed, causing minor injuries to two people (Molinet, 2015). A month later, a woman was knocked unconscious at the Seattle Pride Parade by a small unmanned aircraft that hit a building, subsequently falling on her ("Falling drone knocks woman out," 2015). In that incident, the woman was fortunate that her boyfriend was able to catch her as she fell, but one can readily envisage that she might have suffered more significant injuries if she had hit her head on an object when she fell. In September 2015, an 
11-month old baby was injured by debris from an unmanned aircraft that crashed at a public event in Pasadena, CA (Henry, 2015). Other incidents of small unmanned aircraft hitting buildings and falling to the ground have been reported (for example: Mortimer, 2012; Williams, 2015; Li, 2015), although there does not appear to have been any injuries caused by these events.

The intermediate vehicle of a building is not a defining feature of the issue; in any setting involving unmanned aircraft and people, the aircraft may malfunction and fall on the people below. For example, in early April 2014, an unmanned aircraft struck a female athlete during a triathlon in Geraldton, Western Australia (Taillier, 2014). The aircraft allegedly dropped about $10 \mathrm{~m}$ before hitting the woman. The triathlete fell to the ground, received lacerations to her head, and stated that ambulance personnel removed a piece of the propeller from her head (Grubb, 2014). Small unmanned aircraft have also crashed at prominent sporting events like the US Open tennis tournament (Waldstein, 2015), although in that case no one was injured.

Fatalities are also a possible outcome of UAS malfunctions and operator errors. Below is a short list of UAS and model aircraft-related fatalities:

- In April 2003, an out-of-control model aircraft killed a 14-year-old girl in England (Sapsted, 2003).

- In November 2003, a 41-year-old man was killed while providing flight instruction to the operator of a radio-controlled model helicopter ("Man killed by model helicopter," 2003).

- In March 2013, a radio-controlled helicopter crashed in Borneo, Malaysia, killing an 18-month-old baby ("Baby killed," 2013).

- In July 2013, a man was killed in Japan while operating a Yamaha R-max UAS ("Heli pilot killed in Japan," 2013).

- In September 2013, a 19 year old in New York was killed when his remotecontrolled helicopter "plummeted from the sky," inflicting severe head and neck injuries (Zennie, 2013).

- In Switzerland in 2013, a radio-controlled helicopter struck the 41-year-old man who was operating it, inflicting what was described as "severe head and arm injuries" (Curtis, 2013).

Only the Borneo incident may have involved a free-falling aircraft, which is the focus of this paper. However, the listed accidents occurred when UAS activity was relatively low, so a greater number and variety of accidents can be expected in the future. It is also likely that the listed accidents are not a complete record. It was evident from online searches that historical news reports have been removed from the internet, and it is only those accidents that have been recorded in online discussion forums for which any evidence is currently available. It seems likely that 
this explains the absence of reports for the period 2004-2008 and 2010-2011. The reason for the absence of reports after 2013 is less clear. It is possible that there have been no fatalities during this period, perhaps due to improvement in flight control systems or random chance.

\section{Setting the Safety Goal}

From an economic perspective, the optimal level of safety occurs when the net benefit from sUAS activity is the greatest, with the net benefit denoting gross benefits from conducting the activity being less than (a) the cost of harm and (b) the cost of taking precaution to avoid harm. Equivalently, the optimal level of safety occurs at the least-cost point where cost is comprised of the cost of harm, the cost of precaution, and the opportunity cost of foregone benefits from any reduction in the activity in question (in this case, unmanned aircraft flights). In theory, this optimal level could be achieved by allowing sUAS operators to choose their level of activity and level of precaution, given the knowledge that they will be subject to liability under tort for any harm that does occur.

The person on the ground has no way of knowing the relative level of danger posed by different unmanned aircraft, the skill level of the pilot, whether a particular unmanned aircraft has been properly maintained, or whether it is being operated safely (for example, whether the UAS is being operated with sufficient battery power remaining). These factors all mean that the person on the ground has no way of knowing the appropriate level of precaution to take if an unmanned aircraft flies overhead. In such cases, the appropriate standard of liability is that of strict liability (Shavell, 1980; Davis, 2011), and aviation regulation does indeed impose strict liability for harm caused by anything falling from the sky. Strict liability with contributory negligence is the legal standard in New Zealand (Civil Aviation Act 1990, s97). Jakubiak (1997) summarizes the liability regime that applies to commercial aviation in the United States, concluding that the various doctrines of liability "appear strikingly similar to common-law imposed strict liability".

Strict liability, properly applied, will provide compensation to a person for harm caused, and thereby return them to the equivalent position as if they had not been harmed. The economic concept is that harm plus compensation is equal to no harm occurring. However, there are many reasons why the strict liability regime may not work as ideally theorized. For example, the sUAS operator might not be able to pay the compensation (e.g. being a 15-year-old high school student), a problem that is referred to in the literature as being "judgment proof" (Shavell, 1986). The potential injurer might not face the threat of a suit for harm done because of difficulty in identifying the party causing harm (Shavell, 1984), or because the costs of going to court to obtain compensation may be too high. For these various 
reasons, it is appropriate to impose an ex-ante safety standard (Shavell, 1984), which may specify allowed activities as well as prohibited activities. Furthermore, while the equivalence of compensation may hold economically, from a moral and political position it is better for the harm not to occur in the first place.

A strict liability regime has the desirable outcome that the potential injurer (i.e., the sUAS operator) will optimize both their level of precaution and their activity level (Shavell, 1984). Regulation sets the minimum level of precaution; it acts as a complement to a liability regime that enables parties with a high cost of precaution (including those with a high opportunity cost of foregone benefits) to take only the minimum level of precaution. Additionally, parties with a low cost of precaution may choose a higher level of precaution (Kolstad et al., 1990). Such a regime significantly reduces the likelihood of harm occurring, while enabling an economically optimal outcome. In all cases, the regulated entity is able to optimize its level of activity.

This still leaves the regulator in the position of determining which ex-ante safety rules will achieve the socially optimal level of safety. We can estimate the expected cost of harm, as is done in this paper, and we may be able to estimate the cost of precaution. However, the benefits from the sUAS activity are very difficult to quantify, and change significantly for different activities. What, for example, is the benefit from an unmanned aircraft flown for private recreational purposes over a beach with numerous people on it? There are also difficult value judgments to make. For example, while the benefits from a UAS flown over a beach for private recreational purposes may not be high enough to justify any level of potential harm, is it then acceptable to allow for some degree of harm because the UAS is actually being used to monitor the sea for swimmers that might need rescuing? Similar questions arise regarding a UAS being flown at a public event. If an unmanned aircraft crashes into a crowd watching a tennis match, is that more acceptable if the UAS is being used to capture footage for a television broadcast than if it is being used for private purposes?

Setting the safety goal is therefore an imprecise process that occurs in an environment of incomplete information. Safety standards are set in an iterative process, with regulators adjusting the standard over time in response to lobbying from interest groups and decisions by the courts. Cooter et al. (1979) argue that the evidence produced by litigants and defendants provides judges with the information required to refine the legal standard of precaution over time, and the same argument can be applied to regulatory decision makers. Even if the legal standard of precaution is not initially efficient, it will converge to the efficient level as it is modified in the light of new information.

For the current analysis, this means that the best available indicator of what might be an appropriate level of safety for sUAS operations is the observed level 
of safety in a comparable area of aviation, such as General Aviation. That level of safety has developed as parties optimize their activity levels in an environment where there are safety regulations, a legal liability regime, and where the parties derive benefits from the various aviation activities undertaken. If the observed level of safety in General Aviation is insufficient, the consequential harm will result in prosecutions, liability suits, and public pressure that ultimately results in a stricter level of safety. If that standard is too strict, then there will be ongoing pressure from operators and manufacturers, who will be able to demonstrate that they can safely operate in prescribed areas. Accordingly, for this analysis, the ground fatality rate for General Aviation is adopted as the safety goal.

The form of safety regulation is then set based on the mechanism that causes harm. The analysis presented in this paper concerns the harm that occurs if an unmanned aircraft falls from a given height on to a person below. Other forms of harm, such as cuts from spinning propellers and horizontal impacts, are not considered. It follows that the appropriate safety regulation is the maximum height at which an unmanned aircraft can fly with the safety goal being met; this paper refers to this as the "maximum allowable height."

\section{UAS-Induced Human Harm Model}

UAS have the potential to cause a range of harm and injuries to human beings. The model presented in this section estimates the economic cost of a subset of injuries that might arise from an impact caused by a multi-rotor unmanned aircraft falling from a given height. The model focuses solely on free-fall incidents, which might arise from the following: an impact with a building, a controller failure, a battery failure, or pilot error. Other incidents - such as those in which the unmanned aircraft flies sideways or at an angle into a person - are not considered.

Figure 1 presents a schematic diagram of the main components of the model. Harm, in terms of fatalities and injuries, is determined by the kinetic energy of the aircraft when it hits a person ("impact energy"); kinetic energy is a function of height and the aircraft mass. Impact energy determines the probability of a fatality if a person is hit by the aircraft; relevant studies are reviewed to develop an appropriate probability function for this model. People impacted by the aircraft but not killed will suffer a range of injuries. This model captures some of the Xxxx 


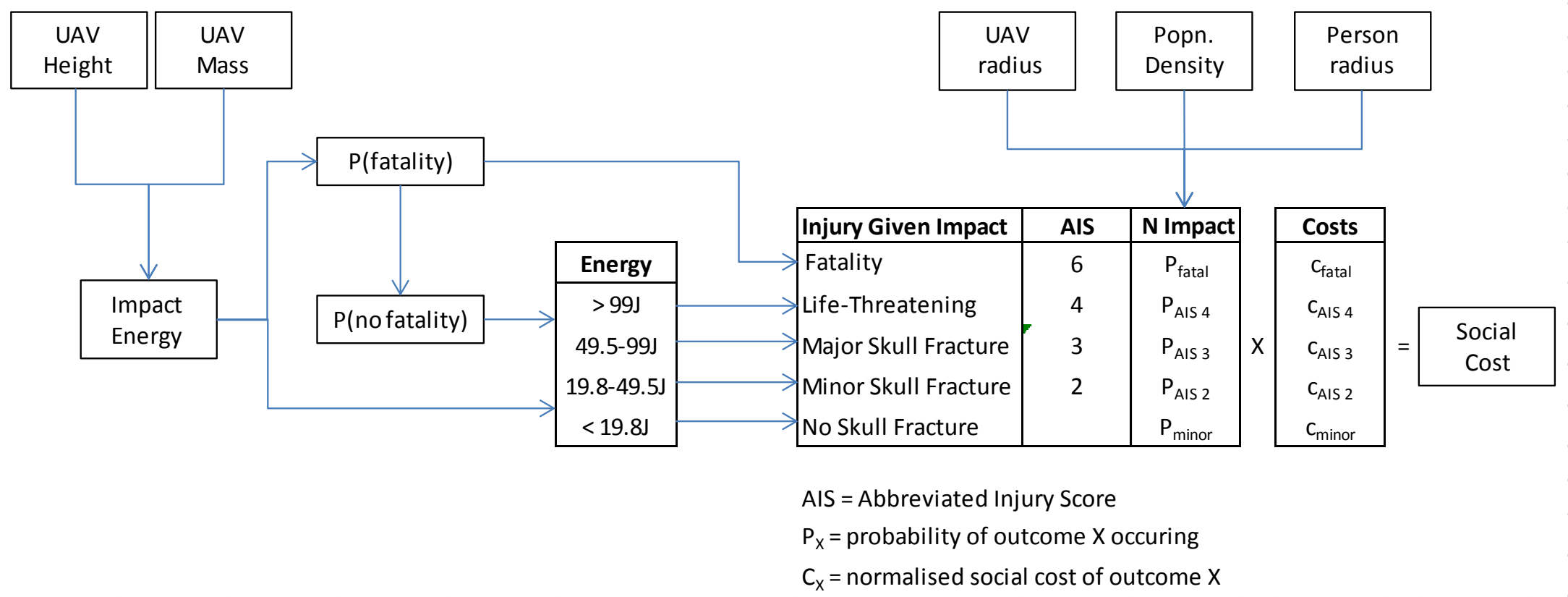

Figure 1. Schematic Diagram of UAS-Induced Human Harm Model. 
more serious injuries, being skull fractures, which are graded according to the commonly used Abbreviated Injury Scale (AIS). Only a subset of potential harm is modelled; injuries similar to the woman knocked unconscious by the unmanned aircraft at the Seattle Pride Parade are not captured by the current version of this model. The model also effectively assumes there is a power failure, so there are no injuries from spinning propellers. The final data required to establish the number of fatalities and injuries per flight hour is the expected number of people exposed to the impact, which is dependent on the population density in the area of operation and the UAS reliability (modelled for convenience as the Mean Time Between Failure).

The rate of ground fatalities from General Aviation in the United States is the safety goal for the model. It develops estimates of the social cost of harm for each type of injury modelled, which are then normalized into a "fatality-equivalent" measure of social cost. Conflating the expected number and type of injuries with the normalized social cost estimates provides the fatality-equivalent cost per flight hour for a given unmanned aircraft operating at a given height. Comparing the fatality-equivalent cost with the safety goal enables the maximum allowable height to be established.

\section{Impact Energy}

Standard physics can be used to estimate the energy with which a falling multi-rotor unmanned aircraft could hit a person. An object free falling through the atmosphere experiences a downward force due to gravity, and an upward drag force due to air resistance. The downward force due to gravity $F_{g}$ is equal to:

$$
F_{g}=m g
$$

where $m$ is the mass of the object and $g$ is the acceleration due to gravity.

The drag force $F_{d}$ is proportional to the square of downwards velocity $v$ of the object, and is equal to (Crowe et al., 2009:365):

$$
F_{d}=\frac{1}{2} c_{D} A \rho_{A} v^{2}
$$

When the two forces are equal, the object will cease to accelerate and is said to have reached terminal velocity. Equating $F_{g}$ and $F_{d}$, and solving for terminal velocity, $v_{T}$, gives:

$$
v_{T}=\sqrt{\frac{2 m g}{c_{D} A \rho_{A}}}
$$


where $C_{D}$ is the drag coefficient, $\rho_{A}$ is the density of air $\left(1.225 \mathrm{~kg} / \mathrm{m}^{3}\right.$ at sea level $)$, $A$ is the cross-sectional area of the object in the direction that it is falling, and the gravitational constant is $g=9.806 \mathrm{~m} / \mathrm{s}^{2}$.

The velocity of the object after falling from height $h$ is, assuming the object is at rest at the start of the free fall (Fowles and Cassiday, 2005:73):

$$
v^{2}=v_{T}^{2}\left(1-e^{-2 g h / v_{T}^{2}}\right)
$$

The impact energy $E_{i m p}$ at velocity $v$ is given by:

$$
E_{\text {imp }}=\frac{1}{2} m v^{2}
$$

For the purpose of this analysis, $h=h_{\text {AIRCRAFT }}-h_{\text {HUMAN }}$, where $h_{\text {AIRCRAFT }}$ is the height of the unmanned aircraft above ground level, and $h_{H U M A N}$ is the height above ground level of the impacted area of a human (i.e. typically the head and shoulders). The height of a human is assumed to be 5'10" $(1.778 \mathrm{~m})$.

The drag coefficient $C_{D}$ depends on the shape and surface roughness of the object. Ball et al. (2012:27) adopt a drag coefficient of 0.5 as typical for military rotor wing aircraft. CASA (2013) does not provide a value for the drag coefficient. Skobir and Magister (2011) focus on a fixed wing unmanned aircraft, so their formula for the drag coefficient is not relevant to a falling multi-rotor aircraft. Dalamagkidis et al. (2008) also focus on a fixed wing aircraft, and avoid specifying a drag coefficient by assuming the impact velocity is $40 \%$ higher than the "maximum operating velocity." The UAS Task Force (2015) adopts a value of $C_{D}$ $=0.3$, and the present analysis adopts the same value.

Six unmanned aircraft sizes are modelled:

- a $150 \mathrm{~g}$ aircraft, which is significantly below the threshold for registration with the FAA;

- a $250 \mathrm{~g}$ aircraft, which is the threshold for registration with the FAA;

- a 500g aircraft;

- a 1.5kg aircraft that is similar to the popular DJI Phantom and 3DR Solo, and slightly lighter than the Yuneec Typhoon $\mathrm{H}$;

- a $3 \mathrm{~kg}$ aircraft; and

- a larger $8 \mathrm{~kg}$ aircraft.

Table 1 provides parameters for each modelled aircraft. Much heavier machines are possible, with the regulated upper limit for a "small" unmanned aircraft being $25 \mathrm{~kg}(55 \mathrm{lb})$. The results of the analysis indicate that even at $8 \mathrm{~kg}$ the safety goal is breached by flying at any height over people at anything other than 
low population densities; and at a low population density the maximum allowable height for the aircraft is a small distance above people's heads. Therefore, there is no additional information to be gained from analyzing heavier aircraft.

Table 1

Modelled Unmanned Aircraft.

\begin{tabular}{lrcccccc}
\hline $\begin{array}{l}\text { Unmanned } \\
\text { Aircraft }\end{array}$ & $\begin{array}{c}\text { Mass } \\
(\mathbf{k g})\end{array}$ & $\begin{array}{c}\text { Diameter } \\
(\mathbf{m})\end{array}$ & $\begin{array}{c}\text { Core D } \\
(\mathbf{m})\end{array}$ & $\begin{array}{c}\text { Core A } \\
\left(\mathbf{m}^{\mathbf{2}}\right)\end{array}$ & $\begin{array}{c}\text { Outer A } \\
\left(\mathbf{m}^{\mathbf{2}}\right)\end{array}$ & $\begin{array}{c}\mathbf{A} \\
\left(\mathbf{m}^{\mathbf{2}}\right)\end{array}$ & $\begin{array}{c}\boldsymbol{v}_{\boldsymbol{T}} \\
(\mathbf{m} / \mathbf{s})\end{array}$ \\
\hline A - $8 \mathrm{~kg}$ & 8 & 1 & 0.16 & 0.020106 & 0.785398 & 0.173165 & 49.65 \\
B - 3kg & 3 & 0.6 & 0.144 & 0.016286 & 0.282743 & 0.069577 & 47.97 \\
C - 1.5kg & 1.5 & 0.4 & 0.12 & 0.011310 & 0.125664 & 0.034181 & 48.39 \\
D - 500g & 0.5 & 0.2 & 0.08 & 0.005027 & 0.031416 & 0.010304 & 50.89 \\
E - 250g & 0.25 & 0.2 & 0.07 & 0.003848 & 0.031416 & 0.009362 & 37.75 \\
F - 150g & 0.15 & 0.12 & 0.07 & 0.003848 & 0.011310 & 0.005341 & 38.71 \\
\hline
\end{tabular}

"Core D" is the diameter of the central core of the aircraft containing the control systems, batteries, etc. "Core A" is the area of the central core. "Diameter" is the diameter of the circle that circumscribes the aircraft, and "Outer A" is the area of that circle. "A" is the area used for the calculation of the drag force and is calculated as $\mathrm{A}=[$ Core $\mathrm{A}]+0.2 \times$ ([Outer $\mathrm{A}]-[$ Core $\mathrm{A}]$ ); it is assumed that only $20 \%$ of the circle outside of the central core has structures that impede airflow.

Figure 2 shows the impact energy from each modelled aircraft, for a free fall from heights up to 400ft above ground level (AGL). This is the maximum height allowed by regulation.

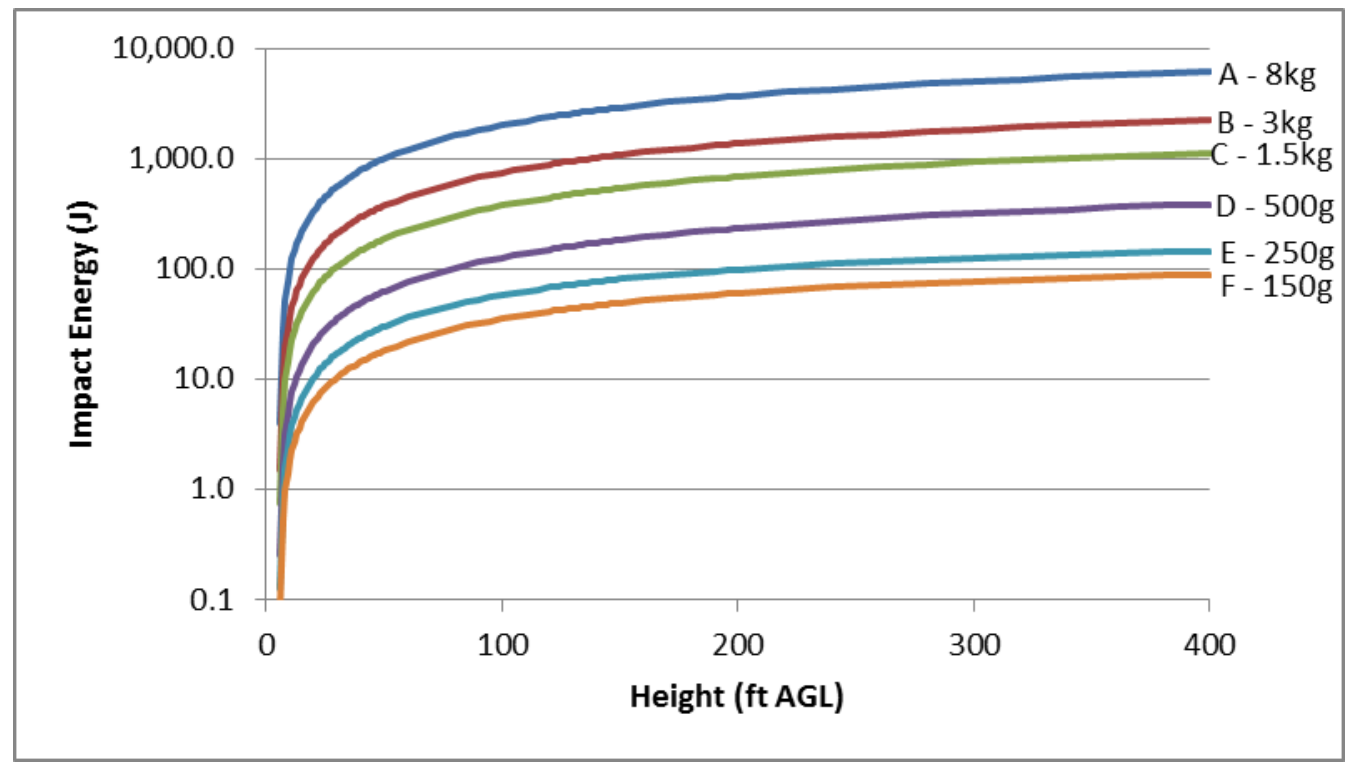

Figure 2. Impact Energy by Modelled Unmanned Aircraft, no parachute. 


\section{Probability of Fatality Given Impact}

This component of the model calculates the probability of a fatality in the event a falling object strikes a person. Given that the object of interest is falling from above, the focus is on fatalities caused by an impact to a person's head.

The simplest approach adopted in the literature is that utilized by the UAS Task Force. It relies on a single point estimate that "an object with a kinetic energy of $80 \mathrm{~J}$... has a $30 \%$ probability of being lethal when striking a person in the head" (UAS Task Force, 2015:8), and on this single point estimate in calculating the maximum weight for an unmanned aircraft that does not require registration. This approach is unsuitable when kinetic energy may differ substantially from the 80J estimate.

Whether or not a fatality occurs is a binary outcome - the impact is either fatal or it is not. When the outcome is binary, it is appropriate to use a logistic curve to model the probability, and the other sources reviewed below take this approach. A logistic curve for the probability of a fatality takes the form:

$$
P(\text { fatality } \mid \text { impact })=\frac{1}{1+e^{-k\left(E_{\text {imp }}-E_{0}\right)}}
$$

where $E_{0}$ is the impact energy associated with a $50 \%$ probability of a fatality and $k$ is a constant.

The origin of the $30 \%$ probability of lethality at $80 \mathrm{~J}$ used by the UAS Task Force is a United Kingdom Ministry of Defense report (Henderson, 2010), which in turn references a Department of Defense Explosives Safety Board (DDESB) Technical Paper (Swisdak et al., 2007). Swisdak et al. (2007) suggest a cumulative log-normal distribution relating fatality probability to kinetic energy based on "average body position data," i.e. not specifically related to an impact to the head. Swisdak et al.'s distribution is based on three data points: $10 \%$ probability of fatality at $51.5 \mathrm{~J}, 50 \%$ probability of fatality at $103 \mathrm{~J}$ (a figure in turn quoted by Henderson (2010)), and 90\% probability of fatality at 203.4J. The parameters of the curve are not provided.

Henderson (2010) presents a chart from a 1982 Swiss paper that shows the probability of lethality, given impact energy to different areas of the body; this data is presented as straight lines on a log-log chart, and implicitly describes a logistic curve. Figure 3 shows data points estimated by eye from the Swiss data (blue diamonds) and the three data points provided by Swisdak et al. (green triangles). Logistic curves have been fitted to both sets of data; the solid line shows the logistic curve for the Swiss data, and the dashed line shows the logistic curve for the Swisdak et al. data. The curve through the Swisdak data predicts relatively lower 
fatality rates at high impact energies, and never reaches a certain probability of fatality, even at very high impact energies. For this reason, the curve fitted to the Swiss data is preferred. The parameters for the curve fitted to the Swiss data are: $E_{0}=103 \mathrm{~J}$ and $k=0.09$.

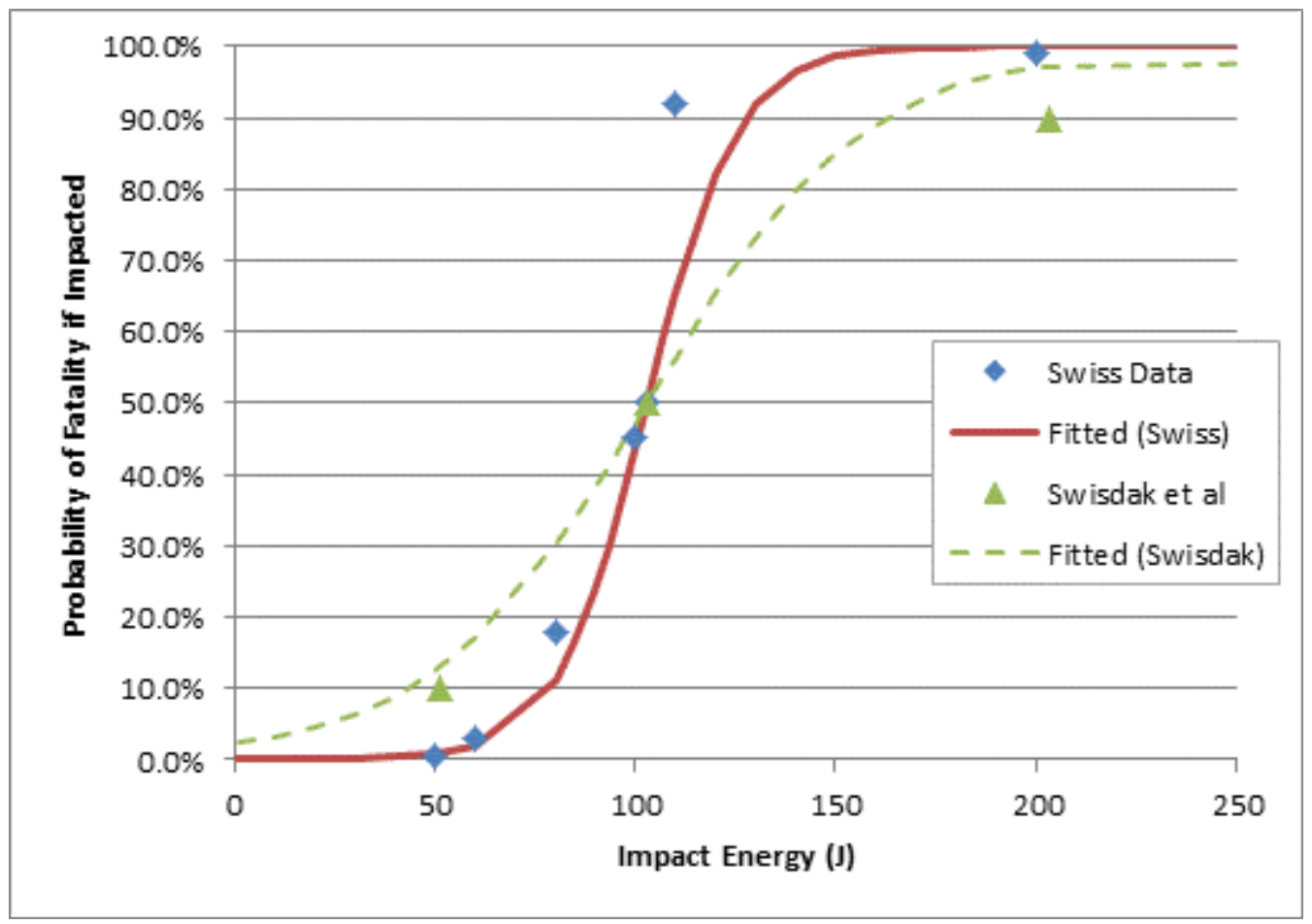

Figure 3. Probability of Fatality: Logistic Curves fitted to Henderson (2010) and Swisdak et al. (2007).

Dalamagkidis et al. (2008) propose a modified form of a logistic model that includes a sheltering parameter, which takes account of the exposed population's ability to take shelter from an impact. A sheltering parameter is appropriate for an analysis, considering the general risks of flying over an area where there may be a range of buildings, plants, and other objects that could shelter people from either direct impact or from debris thrown up by an unmanned aircraft crash. This is exactly the focus of Dalamagkidis et al. However, the sheltering parameter is not relevant to the analysis presented in this paper; it is assumed that the unmanned aircraft is flying above people who are directly exposed to the impact. In such a situation, the sheltering parameter is equal to zero. In the limit as the sheltering parameter approaches zero, the function proposed by Dalamagkidis et al. (2008) becomes a step function that provides a fatality probability of 0 for all impact 
energies less than a specified value, and 1 for all impact energies greater than or equal to that value. This function is therefore unsuitable for the present analysis.

The most suitable approach for this model is the curve fitted to the Swiss data from Henderson (2010), presented in Figure 3 and the accompanying text. Combining the impact energies from Figure 2 and the fatality probability from Figure 3 provides the fatality curves in Figure 4, which shows the probability of a fatality if a person is hit by each modelled unmanned aircraft from any height up to 400ft AGL. Probability is plotted on a logarithmic scale, providing greater detail on the probability associated with the three lighter aircraft.

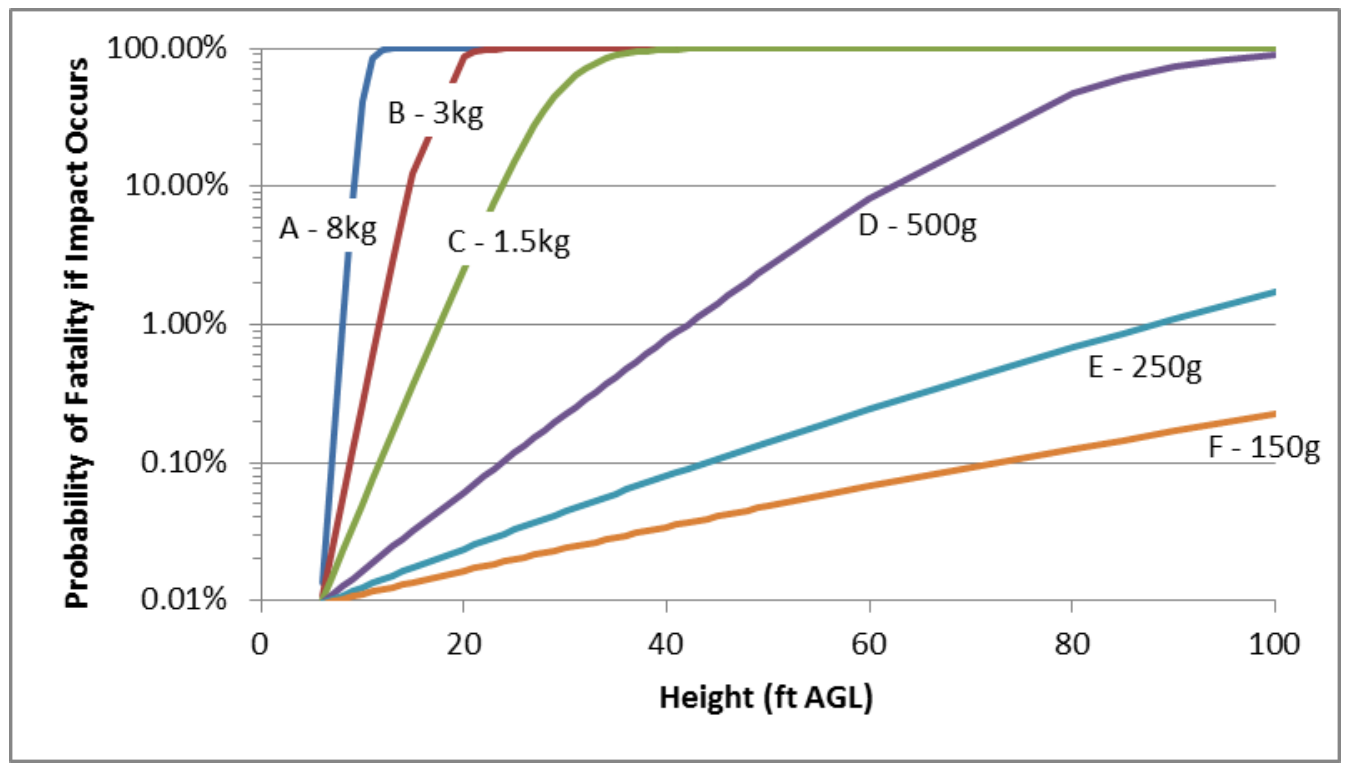

Figure 4. Probability of a Fatality if Impact Occurs, by Aircraft and Height.

\section{Impact Injuries}

People hit by a falling unmanned aircraft, but not fatally injured, may have received injuries of varying severity, depending on the force of the impact. None of the models reviewed above include a prediction of injury severity, but this is essential for a full assessment. The most likely impact injuries are injuries to the head, particularly skull fractures. Information from various sources is used to establish a relationship between impact energy and the severity of a skull fracture.

In a study for establishing the safety of rail cars, Payne and Patel (2001) relate the impact force and injury to two widely used injury scales: the Head Injury Criterion (HIC) and Abbreviated Injury Score (AIS). The HIC is calculated from impact forces experienced by crash-test dummies and will predict the level of injury. The AIS is an injury scoring system that is widely used by hospital 
emergency departments, and, being published by the Association for Advancement of Automotive Medicine (AAAM), is also widely used within accident research. Payne and Patel (2001) propose specific ranges relating impact force to the severity of the injury sustained; Table 2 shows their proposed ranges for "Blunt Object Skull Fractures".

The tolerance levels reported in Table 2 are consistent with the other estimates of force causing skull fracture. Yoganandan et al. (1995) tested twelve un-embalmed, intact human cadaver heads to failure, and found that a fracture occurred with loads ranging from $4.5 \mathrm{kN}$ to $14.1 \mathrm{kN}$, with an overall mean of $6.4 \mathrm{kN}$ $( \pm 1.1)$. In a test of children's bicycle helmets by Mattei et al. (2012), the unhelmeted skull underwent catastrophic failure at a maximum load of 520lbf or $2.3 \mathrm{kN}$ during compression testing (Mattei et al., 2012). Raymond et al. (2009) tested the tolerance of seven cadaver heads to impacts, and found that no fracture occurred at forces of $2.5 \mathrm{kN}-5.0 \mathrm{kN}$ (6 observations) and $6.0 \mathrm{kN}$ (one observation). A linear fracture occurred for one impact of $6.3 \mathrm{kN}$, and depressed skull fractures occurred at forces of $3.4 \mathrm{kN}-9.5 \mathrm{kN}$ (6 observations).

Table 2

Force Required for Skull Fracture Caused by Blunt Object, Payne and Patel (2001).

\begin{tabular}{|l|c|c|c|}
\hline Injury Level & $\begin{array}{c}\text { Tolerance } \\
\text { Level } \\
(\mathbf{k N})\end{array}$ & $\begin{array}{c}\text { Equivalent } \\
\text { HIC }\end{array}$ & $\begin{array}{c}\text { Equivalent } \\
\text { AIS }\end{array}$ \\
\hline 0-1 No Skull Fracture & $<2.2$ & $<500$ & \\
\hline 2 Minor Depressed Skull Fracture & $2.2-5.5$ & $500-900$ & 2 \\
\hline 3 Major Depressed Skull Fracture & $>5.5$ & $900-1800$ & 3 \\
\hline 4 Severe Life-Endangering Fracture & $>5.5$ & $>1800$ & $4 / 5^{*}$ \\
\hline
\end{tabular}

Source: http://www.eurailsafe.net/subsites/operas/HTML/Section3/Section3.3frm.htm. A severe life-endangering fracture is assessed by the authors of the OPERAS study as "potentially nonsurvivable with over $50 \%$ probability of an AIS 4 head injury".

Although the effect of an object dropping on to the top or back of the skull may differ from the effect of a frontal impact, as an initial approximation we adopt the scale shown in Table 2 for potential skull fractures caused by blunt objects falling from the sky. There are two adaptations required to utilize Payne and Patel's ranges in the present analysis: first, a threshold needs to be established for the force at which a skull fracture becomes an AIS level 4/5 fracture rather than AIS level 3; second, it is necessary to relate the impact force to the impact energy. For the first item, the assumption that the threshold between AIS level 3 and AIS level 4/5 occurs at $11 \mathrm{kN}$ of impact force is adopted. 
For the second adaptation, all kinetic energy is dissipated as the object comes to rest, so the average impact force $F$ is:

$$
F=E_{\text {imp }} / d
$$

With this formula, we can readily calculate the force with which a falling aircraft might hit a person. Raymond et al. (2009) find that kinetic (impact) energy and force have a similar ability to predict skull fractures. Their data also indicate that the average value for $d$ is $0.009 \mathrm{~m}$ (i.e. $9 \mathrm{~mm}$ ).

Given the two adaptations indicated, Table 3 shows the relationship between impact energy and injury severity adopted for this model.

Table 3

Assumed Relationship between Impact Energy and Skull Fracture Severity.

\begin{tabular}{lccc}
\hline Outcome & $\begin{array}{c}\text { Impact } \\
\text { Force } \\
(\mathbf{k J})\end{array}$ & $\begin{array}{c}\text { Impact } \\
\text { Energy } \\
\text { Threshold } \\
(\mathbf{J})\end{array}$ & $\begin{array}{c}\text { AIS } \\
\text { Injury } \\
\text { Severity }\end{array}$ \\
\hline No Skull Fracture & & & 0 \\
Minor Depressed Skull Fracture & 2.2 & 19.8 & 2 \\
Major Depressed Skull Fracture & 5.5 & 49.5 & 3 \\
Severe Life-Endangering Fracture & 11 & 99 & 4 \\
\hline
\end{tabular}

\section{Probability of Impact}

An unmanned aircraft that crashes will only injure a person if there is a person in its path as it crashes. The expected number of people impacted or hit in the event of a crash, $N_{\text {exp }}$, is equal to the product of the expected crash area, $A_{\text {exp }}$, and an assumed uniform population density, $\rho$ (Dalamagkidis et al. 2008):

$$
N_{\text {exp }}=\rho \cdot A_{\text {exp }}
$$

$N_{\text {exp }}$ will be a positive real number. If the expected crash area is $0.5 \mathrm{~m}^{2}$ and the population density is 0.2 people $/ \mathrm{m}^{2}$, then the expected number of people hit is 0.1 ; this also means that we would expect one person to be hit every 10 times an unmanned aircraft crashes under conditions that match these assumptions. In a dense setting with a large unmanned aircraft, it is possible that the expected number of people hit in the event of a crash is greater than 1 .

Following Clothier and Walker (2006), Dalamagkidis et al. also suggest that in a vertical crash the area $A_{\text {exp }}$ "may be approximated by the frontal area of the 
aircraft augmented by a small buffer to account for the width of an average human." Assuming, for simplicity, that a human has a circular cross section, the formula for the expected number of people affected by a vertical crash is:

$$
N_{\exp }=\rho \cdot \pi \cdot\left(r_{\text {AIRCRAFT }}+r_{\text {HUMAN }}\right)^{2}
$$

where $\pi$ has its usual value, $r_{\text {AIRCRAF }}$ is the radius of the aircraft, and $r_{\text {HUMAN }}$ is the radius of the human being.

Oberhagemann (2012) cites a German-language source from 1993 as providing an estimate of the surface area, as viewed from above of an "average citizen of Central Europe" of $0.085 \mathrm{~m}^{2}$, which corresponds to a radius of $0.164 \mathrm{~m}$. A value of $r_{\text {human }}=0.164 \mathrm{~m}$ is therefore assumed for this model. Table 1 provides the diameter from which the radius of the unmanned aircraft is derived.

Oberhagemann (2012) also provides useful indications of potential crowd densities: photographs of crowds in the public viewing area of the football World Cup in 2006 show densities of 3.8 people $/ \mathrm{m}^{2}$ and 5.0 people $/ \mathrm{m}^{2}$. Still (2013) provides additional graphic representations of crowd densities. Given the densities portrayed in these various images, the present analysis adopts densities ranging from 0.05 people $/ \mathrm{m}^{2}$ to 4 people $/ \mathrm{m}^{2}$.

\section{UAS Failure Rate}

This is an important parameter of the model, yet there is no data available to justify any particular rate. The UAS Task Force (2015) assumes a Mean Time Between Failure (MTBF) of 100 hours, and the same assumption is employed here. A sensitivity analysis is also conducted with an MTBF of 1000 hours.

\section{Safety Goal}

As discussed in section 0 , the safety goal adopted in this analysis is set equal to the ground fatality rate for General Aviation in the United States. Table 7 in the appendix shows fatalities and fatality rates for General Aviation in the United States between 1995 and 2014. The difference between total fatalities and fatalities for those aboard the aircraft provide the fatality rate for those people killed in an accident who were not aboard the US-registered aircraft. The average fatality rate

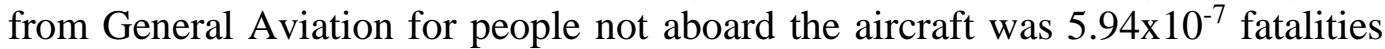
per flight hour over this period. However, it should also be noted that this fatality rate is inflated by the inclusion of 154 fatalities from a non-US registered aircraft in the "Not Aboard" fatality rate; removal of these 154 fatalities results in a fatality rate of $2.31 \times 10^{-7}$ for people not aboard the US-registered aircraft. Both figures are in the same order of magnitude as, but larger than, the ground fatality rate of $1.0 \times 10^{-}$ 
${ }^{7}$ fatalities per flight hour that is adopted by Dalamagkidis et al. (2008), which was based on similar data to that in Table 7, albeit for a longer period.

The UAS Task Force (2015:9) suggests that the "actual risk level" for General Aviation is in the order of $5 \times 10^{-5}$, without defining precisely what that term means. In the context of their analysis, this would appear to refer to the risk of fatality. However, the rate of $5 \times 10^{-5}$ is approximately two orders of magnitude higher than the ground fatality rate in the data, and twice the total fatality rate. The conclusions of the UAS Task Force could therefore be biased towards accepting a higher level of risk than that currently posed by manned aviation.

Absent of any public outcry about risk of General Aviation to members of the public, the rate of $5.94 \times 10^{-7}$ fatalities per flight hour forms a reasonable starting point for the acceptable level of risk to the public from sUAS. This analysis therefore adopts a rounded value of $6 \times 10^{-7}$ fatality-equivalents per flight hour for the safety goal. The lower rate of $2.31 \times 10^{-7}$ could also have been adopted, which could lead to more stringent recommendations than those presented in this paper.

\section{Estimates of Social Cost}

Social cost is the appropriate tool for converting the various injuries into a common estimate of harm. Cost estimates can then be normalized to provide an injury score that relates to social welfare. An important component of the social cost is the number of "Quality-Adjusted Life Years" (QALYs) lost, which provides a quantitative estimate of the duration and severity of a health problem. The monetary value of a QALY is determined by the statistical value of a life, and the average life span (Zaloshnja et al., 2004:424).

Studies involving the cost of treating injuries usually focus on very broad categories of injury rather than the level of granularity required for this model; and, they typically focus on monetary costs and omit QALYs lost. For example, Polinder et al. (2005) estimate the cost of hospital admissions for age bands, gender, and for broad categories of injury such as "hip fracture," "fracture: knee/lower leg," and "skull-brain injury." While the latter category is relevant to this analysis, it does not differentiate on the severity of injury. Chen et al. (2012) estimated the direct costs of "Acquired Brain Injury" in Ontario, Canada, but were only concerned with the difference in cost between TBI (i.e. resulting from an accident) and a non-traumatic brain injury); they did not include severity scores in their analysis. 
In New Zealand, Pezzullo and Crook (2006) undertake a comprehensive estimation of the costs associated with occupational disease and injury, including lost productivity, lost human capital, medical costs, administrative costs, the deadweight cost of administering the welfare system, other government transfers, and other costs. However, the measure of severity adopted by this study is the length of absence from work, a measure that is not relevant to the current analysis. The New Zealand Ministry of Transport (MOT) estimates the "social cost" of road accidents in New Zealand, using estimates of QALYs lost, lost productivity, medical treatment costs, and legal costs (MOT, 2016). QALYs lost utilizes annually updated estimates of the value of a statistical life, based on the willingness-to-pay to avoid one premature death. The MOT provides estimates in three categories: (i) fatality; (ii) serious harm or notifiable injury including bone fracture, laceration, or burns; and (iii) minor harm.

Zaloshnja et al. (2004) was the only study found that relates economic costs to AIS scores; Table 4 provides estimates from Zaloshnja et al. (2004). The "Comprehensive Cost" is the total cost including QALYs lost. The cost of property damage is deducted from the Comprehensive Cost, as in most of the situations contemplated by the current analysis; the only property damaged would be the unmanned aircraft. The cost excluding property damage is then normalized to the cost of a fatality.

Table 4

Normalized Social Cost calculated from Zaloshnja et al. (2004), USD.

\begin{tabular}{lrrrrc}
\hline Human Harm & $\begin{array}{c}\text { Comprehensive } \\
\text { Cost }\end{array}$ & $\begin{array}{c}\text { Property } \\
\text { Damage }\end{array}$ & $\begin{array}{c}\text { Cost excl } \\
\text { Property } \\
\text { Damage } \\
\text { (USD) }\end{array}$ & $\begin{array}{c}\text { Normalized } \\
\text { to Fatality }\end{array}$ & $\begin{array}{c}\text { Normalized } \\
\text { Social Cost } \\
\text { for model }\end{array}$ \\
\hline Death & $3,158,552$ & 10,273 & $3,148,279$ & 1.000 & 1.0 \\
Skull Fracture & & & & & \\
- AIS 4 & $1,042,400$ & 9,833 & $1,032,567$ & 0.328 & 0.3 \\
- AIS 3 & 374,316 & 6,799 & 367,517 & 0.117 & 0.1 \\
- AIS 2 & 310,706 & 3,954 & 306,752 & 0.097 & 0.1 \\
Minor $(*)$ & 500 & & 500 & 0.000159 & 0.0002 \\
\hline
\end{tabular}

(*) For the purposes of the current analysis, the cost of a minor injury is set at a nominal \$500USD.

The data set utilized by Zaloshnja et al. (2004) is truncated, because it will not include instances of non-physical harm such as fright or annoyance; nor will it include very minor injuries. The cost for minor harm must be positive, but we do not have an estimate of its value. This analysis therefore adopts a nominal value of 
\$500USD; further analysis of the significance of this is provided below, when considering social cost estimates for New Zealand.

As indicated by the regulators discussed in the introduction, this paper is also concerned with the application of the results of the Human Harm Model to sUAS regulation in New Zealand. The data from MOT (2016) can be scaled using the values reported in Zaloshnja et al. (2004) to estimate New Zealand dollar (NZD) values for each severity of injury. Thus, we can calculate a normalized cost per AIS level. MOT (2016) provides cost estimates in NZD for fatalities.

Table 5 shows the resulting social cost estimates. The final two rows of the table normalize the social cost estimates to that of a fatality, rounded to one significant digit to recognize the imprecision in the estimates. The normalized social costs for AIS severity 2 and AIS severity 3 injuries are 0.05 of the social cost of a fatality, whereas the normalized social cost for AIS severity 4 injuries are 0.4 of the social cost of a fatality. The NZD value social cost estimates for skull fracture injuries were derived by scaling each cost component from MOT (2016) with the data reported in Zaloshnja et al. (2004). Table 5 provides the scaled cost estimates; the scaling applied to each cost component is described in the table's notes. The final row of Table 5 reports the normalized social cost.

As noted above with the data from Zaloshnja et al. (2004), the costs reported in MOT (2016) for "minor" injuries are derived from a truncated data set, and are therefore likely to overstate the average cost of minor injuries. The data set will not include instances where no harm occurred, nor where there were no (or minor) medical costs, and no legal and court costs. Disability and loss of output in such circumstances will also be overstated. The true normalized figure is likely to range between 0 and 0.04. The results of the Human Harm Model are sensitive to the value assumed. Take, for example, the smallest of the aircraft modelled. When falling from a height of $10 \mathrm{ft}$ AGL, the impact energy when hitting a person is $1.85 \mathrm{~J}$; there is zero probability of fatality and no skull fracture occurs. The expected cost is therefore 0.004 per person impacted. At a population density of 0.05 people $/ \mathrm{m}^{2}$ there are 0.015 people expected to be impacted. With a MTBF of 100 hours, the expected cost is $0.004 \times 0.015 / 100=6 \times 10^{-7}$ per hour, exactly equal to the safety goal of $6 \times 10^{-7}$ per hour. This suggests that a $150 \mathrm{~g}$ aircraft should not be flown at heights greater than $10 \mathrm{ft}$ AGL above relatively low densities, even when we know intuitively that little harm would occur. This analysis therefore adopts a nominal value of $\$ 500 \mathrm{NZD}$ for the average value of harm that occurs, to cover outcomes such as fright, annoyance, and loss of enjoyment of activities. This normalizes to a value of 0.0001 , and for the example given provides an expected social cost of $1.5 \times 10^{-8}$ per hour, well below the safety goal. 
Table 5

Calculation of Normalized Social Cost for New Zealand, NZD.

\begin{tabular}{|c|c|c|c|c|c|}
\hline \multirow{2}{*}{ Cost Component } & \multirow{2}{*}{ Fatal } & \multicolumn{3}{|c|}{ Skull Fracture Injury } & \multirow{2}{*}{ Minor } \\
\hline & & AIS 4 & AIS 3 & AIS 2 & \\
\hline Loss of Life / Permanent Disability ${ }^{[1]}$ & $4,057,300$ & $1,435,348$ & 149,700 & 155,830 & 16,200 \\
\hline $\begin{array}{l}\text { Loss of Output (Temporary } \\
\text { Disability) }\end{array}$ & - & 31,000 & 29,432 & 27,493 & 300 \\
\hline \multicolumn{6}{|l|}{ Medical } \\
\hline - Hospital/medical ${ }^{[3]}$ & 3,600 & 14,745 & 10,805 & 6,864 & 100 \\
\hline - Emergency/pre-hospital ${ }^{[4]}$ & 2,900 & 2,890 & 1,281 & 738 & 600 \\
\hline - Follow-on ${ }^{[5]}$ & - & 7,290 & 5,342 & 3,393 & 100 \\
\hline Legal and Court ${ }^{[6]}$ & 24,000 & 9,170 & 7,519 & 5,673 & 800 \\
\hline Total & $4,087,800$ & $1,500,442$ & 204,078 & 199,991 & 18,100 \\
\hline Normalized Social Cost & 1.0 & 0.4 & 0.05 & 0.05 & 0.004 \\
\hline
\end{tabular}

Source: "Fatal" and "Minor" from Ministry of Transport (2016).

Notes: Costs for AIS injury levels scaled as follows:

[1] "Loss of Life/Permanent Disability" costs were scaled from the MOT (2016) estimate for a fatality using Zaloshnja et al.'s estimates for "Quality of Life". Zaloshnja et al.'s estimates for "Quality of Life" are \$73,191 (AIS 2), \$70,312 (AIS 3), \$674,162 (AIS 4), and \$1,905,655 (fatal). The Permanent Disability costs for a skull fracture in New Zealand are therefore calculated as $\$ 4,057,300 \times(73,191 / 1,905,655)=\$ 155,830$ (AIS 2); $\$ 4,057,300 \times(70,312 / 1,905,655)=\$ 149,700$ (AIS 3); and $\$ 4,057,300 \times(674,162 / 1,905,655)=\$ 1,435,348$ (AIS 4).

[2] "Loss of Output" was scaled from the MOT (2016) estimate for a fatality using Zaloshnja et al.'s estimates for "Household Work" and "Wage Work".

[3] "Hospital/medical" costs were scaled from the MOT (2016) estimate for a minor injury using Zaloshnja et al.'s estimates for "Medical" costs. Scaling was tested for both a fatal injury and a minor injury. The scaled estimates using fatal costs were substantially higher than the scaled estimates for a serious injury in the MOT analysis, whereas the scaled estimates using a minor injury were in the same relative order of magnitude.

[4] "Emergency/pre-hospital" medical costs were scaled from the MOT (2016) estimate for a fatal injury using Zaloshnja et al.'s estimates for "Police \& Fire".

[5] "Follow-on" medical costs were scaled from the MOT (2016) estimate for a minor injury using Zaloshnja et al.'s estimates for "Medical"; scaling could not be performed using the estimate for a fatal injury because there are no follow-on medical costs in the event of a fatality.

[6] "Legal and Court" costs were scaled from the MOT (2016) estimate for a fatality using Zaloshnja et al.'s estimates for "Legal/Court". 


\section{Results and Discussion}

The Human Harm Model was used to calculate the expected Normalized Social Cost at heights from $6 \mathrm{ft}$ AGL to 400ft AGL in 20ft increments, and for population densities from 0.05 to 4 people $/ \mathrm{m}^{2}$. Results from the Human Harm Model were tabulated; subsequently, interpolation was employed to estimate the maximum height at which the safety goal of $6 \times 10^{-7}$ fatality-equivalents per flight hour was met. Figure 5 shows the maximum allowable height using the normalized social cost for New Zealand, and Figure 6 shows the maximum allowable height using the normalized social cost for the United States. The maximum allowable height at low population densities is essentially the same for the two countries; but, at higher population densities, the New Zealand estimates allow operation at lower levels over higher densities.

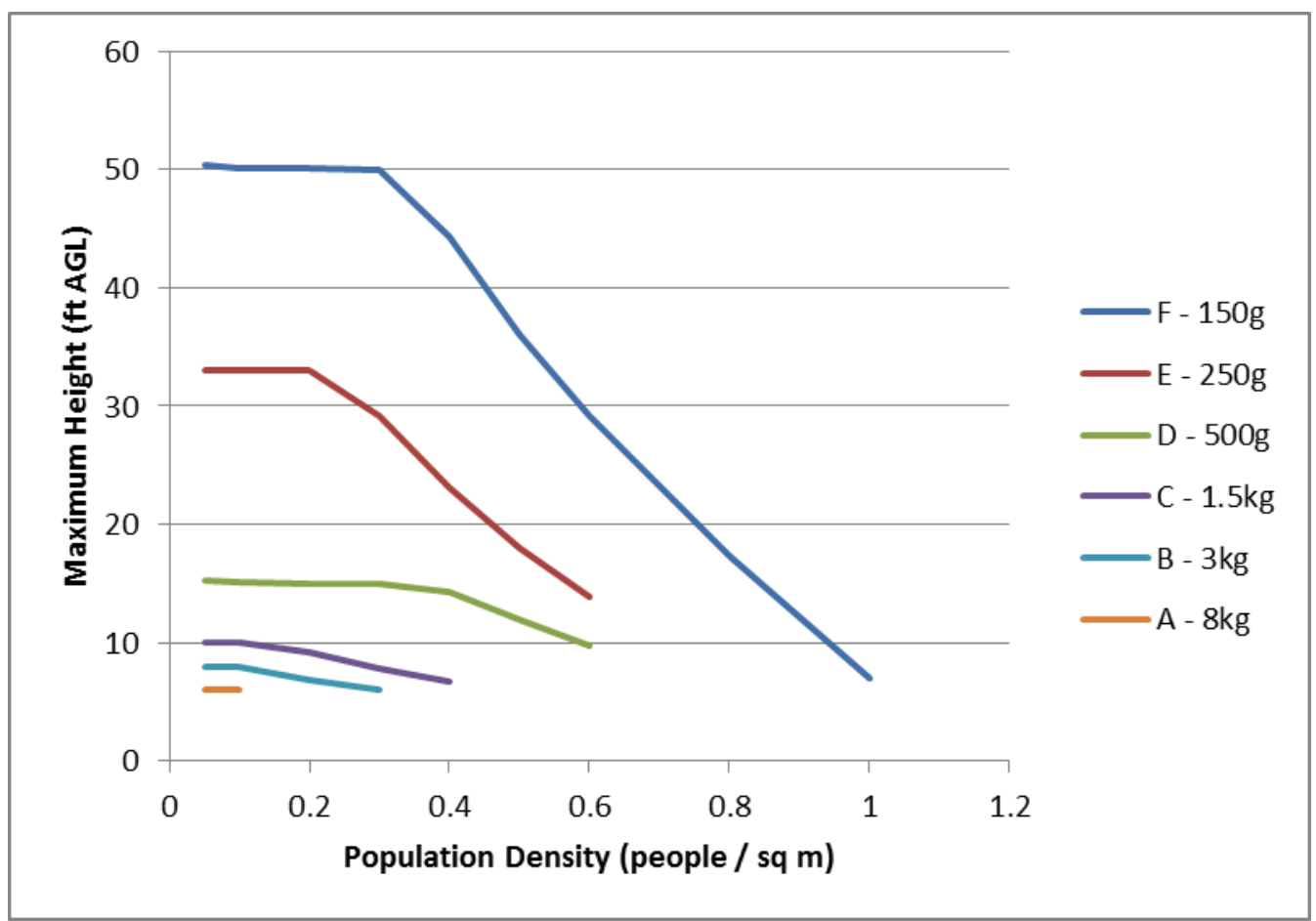

Figure 5. Maximum Allowable Height by Aircraft Size and Population Density, NZ Normalized Social Cost. Source: Table 8 (appendix). 


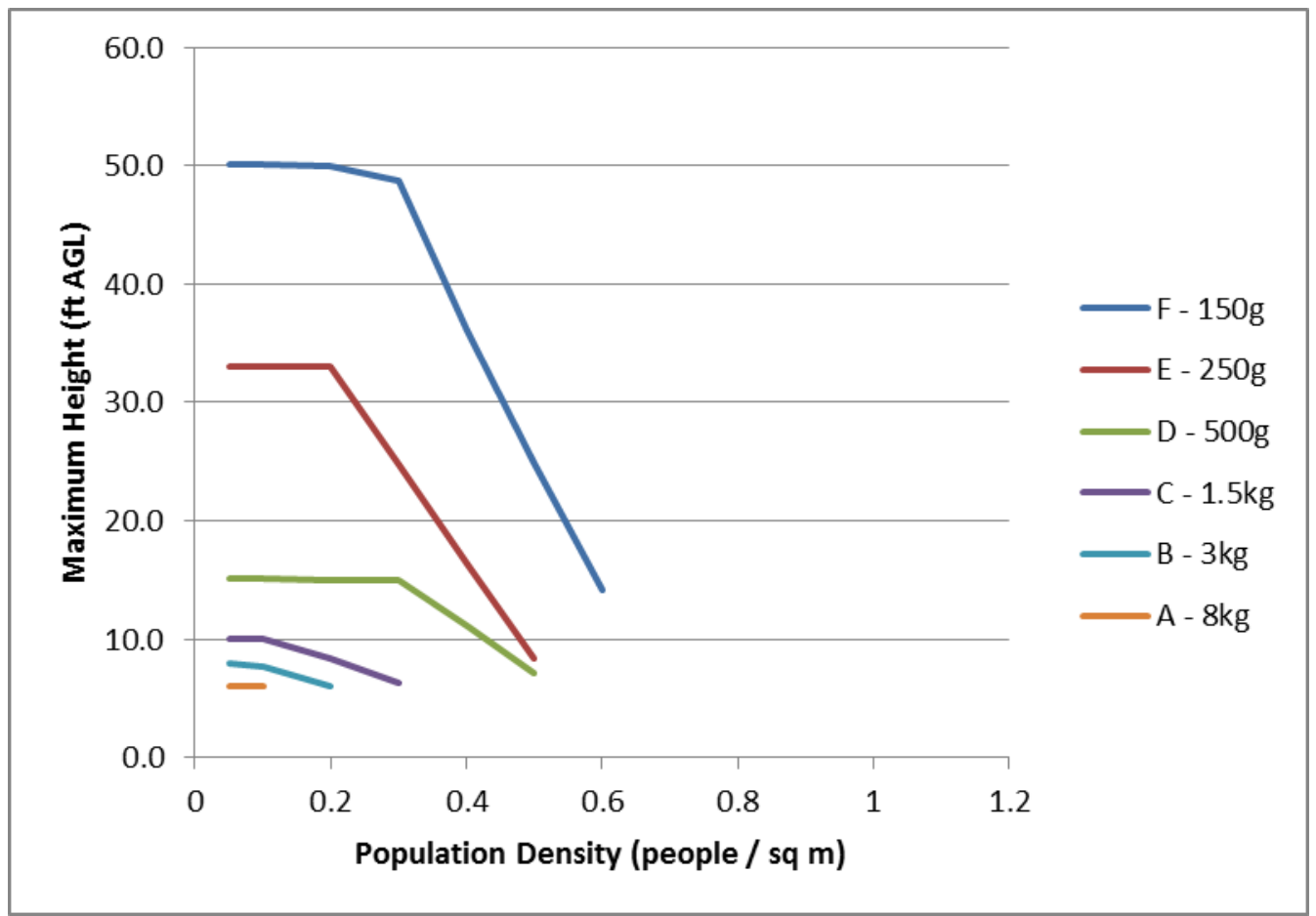

Figure 6. Maximum Allowable Height by Aircraft Size and Population Density, US Normalized Social Cost. Source: Table 8 (appendix).

In a practical sense, any maximum height that is below 10ft AGL should be discarded, as it is too easy for a person on the ground to interfere with a small unmanned aircraft at such low heights. For both countries, this suggests that an aircraft weighing more than $1.5 \mathrm{~kg}$ should not be flown above people at any density; and a $1.5 \mathrm{~kg}$ aircraft can be flown at $10 \mathrm{ft}$ AGL at low densities. The $500 \mathrm{~g}$ aircraft can be flown above people, but at a maximum height of 15ft AGL (both countries) at densities of 0.3 people $/ \mathrm{m}^{2}$ or less, and at lower heights over a density of not more than 0.6 people $/ \mathrm{m}^{2}$ (New Zealand) or 0.4 people $/ \mathrm{m}^{2}$ (United States). The $250 \mathrm{~g}$ aircraft can also be flown above people, but at a maximum height of $33 \mathrm{ft}$ AGL (both countries) rather than the 400ft AGL suggested by the UAS Task Force. Again, the $250 \mathrm{~g}$ aircraft should not be flown over densities greater than 0.6 people $/ \mathrm{m}^{2}$ (New Zealand) or 0.4 people $/ \mathrm{m}^{2}$ (United States). Even the smaller $150 \mathrm{~g}$ aircraft is restricted to a maximum height of 50ft AGL above relatively low population densities. 


\section{Comparison with UAS Task Force and Micro UAS ARC}

On 16 December 2015, the FAA issued Interim Final Rule 80 FR 78593, requiring the registration of all unmanned aircraft weighing more than $250 \mathrm{~g}$. The $250 \mathrm{~g}$ weight requirement was set on the basis of analysis by the UAS Task Force of ground fatalities per hour of operation, assuming a free fall from 500ft. The results in Figure 6 suggest a considerably different outcome than that derived by the UAS Task Force. The difference between the UAS Task Force and the current analysis arises from two sources: first, the safety goal adopted by the UAS Task Force is based on a ground fatality rate approximately 100 times higher than the actual ground fatality rate; second, the UAS Task Force assumes a very low rate of people exposed to the falling aircraft.

The UAS Task Force assumed a population density of 0.0039 people $/ \mathrm{m}^{2}$ and that just $20 \%$ of that population is exposed to the falling aircraft. An American Football field is $360 \mathrm{ft}(109.73 \mathrm{~m})$ long and $160 \mathrm{ft}(48.77 \mathrm{~m})$ wide (NFL, 2015), so it has an area of $5,351.5 \mathrm{~m}^{2}$. The assumptions employed by the UAS Task Force are equivalent to just four people evenly spaced on that field. The probability of hitting a person in the event of a failure is obviously very low, and in part drives the results of both the UAS Task Force and the Micro UAS ARC in recommending no restrictions on unmanned aircraft weighing $250 \mathrm{~g}$ or less. During a football game, each team has 11 players on the field, and there may be 7 officials on the field; considering these 29 people alone, the density of unsheltered people is over 7 times higher than that assumed by the UAS Task Force. The density obviously becomes much higher again when the total number of players on each team, the coaches, and spectators are considered.

Figure 7 shows the effect of relaxing the safety goal to the value assumed by the UAS Task Force: all modelled unmanned aircraft are able to fly at $500 \mathrm{ft}$ AGL over areas of low population density, and all aircraft are able to operate at greater heights over people at higher population densities.

The UAS Task Force results are reasonable in the context of considering whether an unmanned aircraft should be able to fly over a populated area with people conducting normal day-to-day tasks, many of them inside buildings or vehicles. However, those results substantially understate the risks of flying above crowds, or even above loose groups of people. A $1.5 \mathrm{~kg}$ unmanned aircraft flying above a crowded sidewalk, for example, would pose an unacceptably high risk, whereas the same aircraft flying across houses and backyards with few people outside would likely pose an acceptable level of risk. 


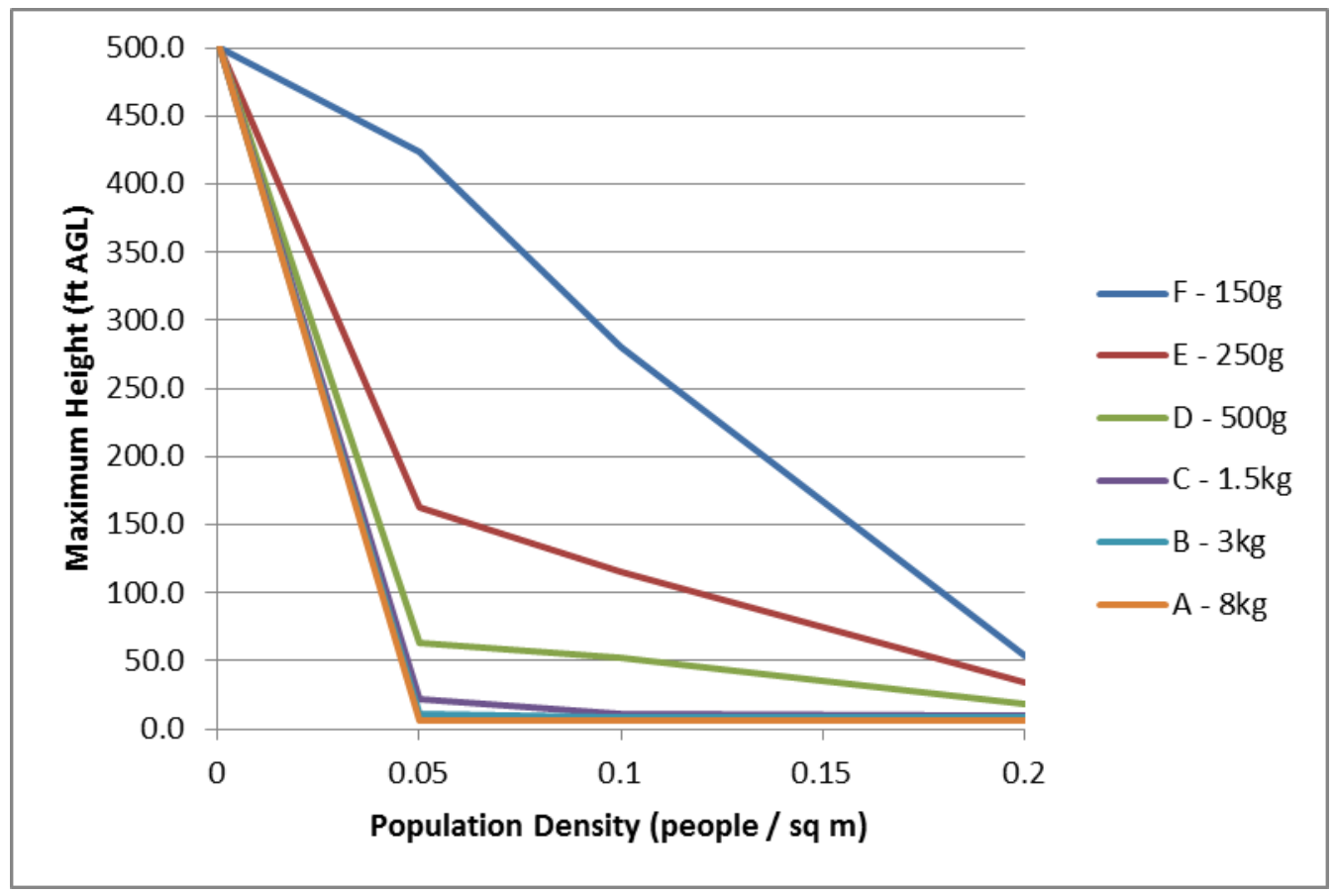

Figure 7. Maximum Allowable Height by Unmanned Aircraft Size and Population

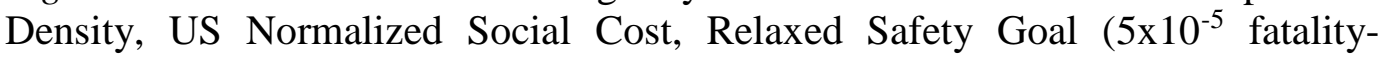
equivalents per flight hour). Source: Table 8 (appendix).

\section{Effect of Parachutes}

On 1 August 2015, New Zealand introduced a new Civil Aviation Rule Part 102 providing for certification of UAS operators. Certification is not required for operators who intend to operate within the rules specified for model aircraft in CAR Part 101, but is mandatory for those operators who want to operate outside the constraints of those rules. The CAA may authorize a departure from the CAR Part 101 model aircraft rules if it considers that there are sufficient mitigations in place to keep risk at an acceptable level. The CAA notes that in "deciding whether to relax or remove the requirement to obtain consent," one of the considerations would include "system redundancy (such as an acceptable automatic recovery parachute)" (CAA, 2015:8).

Parachutes are an effective way of reducing the descent speed of an unmanned aircraft that has suffered a power failure. The actual speed of descent will depend on the relative size of the parachute and mass of the aircraft. The DJI "DropSafe" parachute system results in a descent speed ranging from $4.4 \mathrm{~m} / \mathrm{s}$ for a $3 \mathrm{~kg}$ aircraft to $11.7 \mathrm{~m} / \mathrm{s}$ for a $15 \mathrm{~kg}$ aircraft (DJI, 2015). Opale Paramodels recommends parachutes be appropriately sized so that the maximum descent rate is 
$5.2 \mathrm{~m} / \mathrm{s}$, even with an aircraft as heavy as $40 \mathrm{~kg}$ (Opale Paramodels, n.d.). Parachute manufacturer Fruity Chutes suggests a target descent speed of $4.6 \mathrm{~m} / \mathrm{s}$ (FruityChutes.com, 2016), which is the descent speed used in this analysis.

A maximum descent speed of $4.6 \mathrm{~m} / \mathrm{s}$ significantly lowers the impact energy of the unmanned aircraft, and consequently the injuries that might result if the aircraft hits a person. This in turn makes a significant difference in the maximum allowable height for most of the unmanned aircraft modelled. Table 6 shows the maximum allowable heights with the application of the New Zealand normalized social cost estimates. The small $150 \mathrm{~g}$ aircraft can safely operate at $400 \mathrm{ft}$ AGL above population densities up to 0.8 people $/ \mathrm{m}^{2}$, but not at densities greater than that. Given the densities modelled, the $250 \mathrm{~g}$ and $500 \mathrm{~g}$ aircraft can safely operate at population densities up to 0.6 people $/ \mathrm{m}^{2}$; and the $1.5 \mathrm{~kg}$ aircraft can safely operate with a parachute at densities no greater than 0.1 people $/ \mathrm{m}^{2}$. The parachute enables the $3 \mathrm{~kg}$ aircraft to operate at $400 \mathrm{ft}$ AGL, given the density assumptions adopted by the UAS Task Force, but the $8 \mathrm{~kg}$ aircraft is unsafe to fly over people at any density modelled.

These results indicate that for some unmanned aircraft, a parachute is sufficient to reduce risk to a level sufficient to fly up to the maximum height of 400ft AGL without obtaining consent from those below. However, even for the lighter unmanned aircraft, a parachute is insufficient to mitigate the risk of flying over a crowd.

Table 6

Maximum Allowable Height by Aircraft Size and Population Density, NZ Normalized Social Cost, with Parachute.

\begin{tabular}{lllllllllll}
\hline \multicolumn{1}{c}{ Population Density $\left(\right.$ people/m $\left.\mathbf{m}^{2}\right)$} \\
& $\mathbf{1}$ & $\mathbf{0 . 8}$ & $\mathbf{0 . 6}$ & $\mathbf{0 . 5}$ & $\mathbf{0 . 4}$ & $\mathbf{0 . 3}$ & $\mathbf{0 . 2}$ & $\mathbf{0 . 1}$ & $\mathbf{0 . 0 5}$ & $\mathbf{0 . 0 0 0 7 8}$ \\
\hline F - 150g & 7.0 & 400 & 400 & 400 & 400 & 400 & 400 & 400 & 400 & 400 \\
E - 250g & --- & --- & 400 & 400 & 400 & 400 & 400 & 400 & 400 & 400 \\
D - 500g & --- & --- & 400 & 400 & 400 & 400 & 400 & 400 & 400 & 400 \\
C - 1.5kg & --- & --- & --- & --- & 6.7 & 7.9 & 9.6 & 400 & 400 & 400 \\
B - 3kg & --- & --- & --- & --- & --- & 6.0 & 6.8 & 8.0 & 8.0 & 400 \\
A - 8kg & --- & --- & --- & --- & --- & --- & -- & 6.0 & 6.0 & 6.9 \\
\hline
\end{tabular}




\section{Failure Rate}

The assumed failure rate for all of the analysis presented above is an MTBF of 100 hours. Figure 8 shows the effect of an increase in reliability to an MTBF of 1,000 hours for the $250 \mathrm{~g}$ and $1.5 \mathrm{~kg}$ aircraft. Intuitively, an increase in reliability would allow safe operation at a greater height above ground level over any given population density. This would manifest as (i) allowing greater heights above ground level for population densities where flight is allowed with $\mathrm{MTBF}=100$, and (ii) allowing flight above some population densities that are disallowed at $\mathrm{MTBF}=100$. However, as shown in Figure 8, the first of these cases does not occur: the maximum allowable height for the unmanned aircraft does not change, but each is able to fly at its maximum allowable height over much greater densities of people. The $1.5 \mathrm{~kg}$ aircraft can still only safely fly at a maximum of 10ft AGL over people, but can now do so at maximum densities of 1.5 people $/ \mathrm{m}^{2}$. The $250 \mathrm{~g}$ aircraft remains restricted to $33 \mathrm{ft}$ AGL over people, but is able to fly at that height over densities of up to 2 people $/ \mathrm{m}^{2}$, decreasing to $16 \mathrm{ft}$ AGL over crowds of 4 people $/ \mathrm{m}^{2}$.

This seemingly counter-intuitive result arises because of significant nonlinearities in the expected cost curve. Figure 9 shows the expected cost, conditional upon an impact occurring, for each aircraft by height AGL. Each curve has a step function below a cost of approximately 0.1 . This step reflects the point at which the kinetic energy of impact first exceeds the level at which the lowest grade skull fracture (AIS 2) occurs, and the normalized social cost of this injury is 0.1 (Table 4).

The expected cost per flight hour for each aircraft is derived by dividing the expected cost, given impact by the MTBF, and multiplying by the number of people expected to be hit in the event of a crash. Given the 0.01 threshold for an AIS level 2 skull fracture, if 1 person is expected to be hit in a crash, then an MTBF of 100 results in an expected cost per flight hour of $0.1 / 100 \times 1=1 \times 10^{-3}$; and an MTBF of 1,000 results in an expected cost of $1 \times 10^{-4}$ per flight hour. If only 0.1 people are expected to be hit in a crash, then the expected cost per flight hour is one order of magnitude less. In all four cases, the safety goal of $6 \times 10^{-7}$ fatality-equivalents per flight hour is several orders of magnitude less than these threshold values, and intercepts the approximately vertical section of the expected cost curve. As the curve is approximately vertical in this section, the maximum allowable height will not change significantly; even though reliability has increased. 


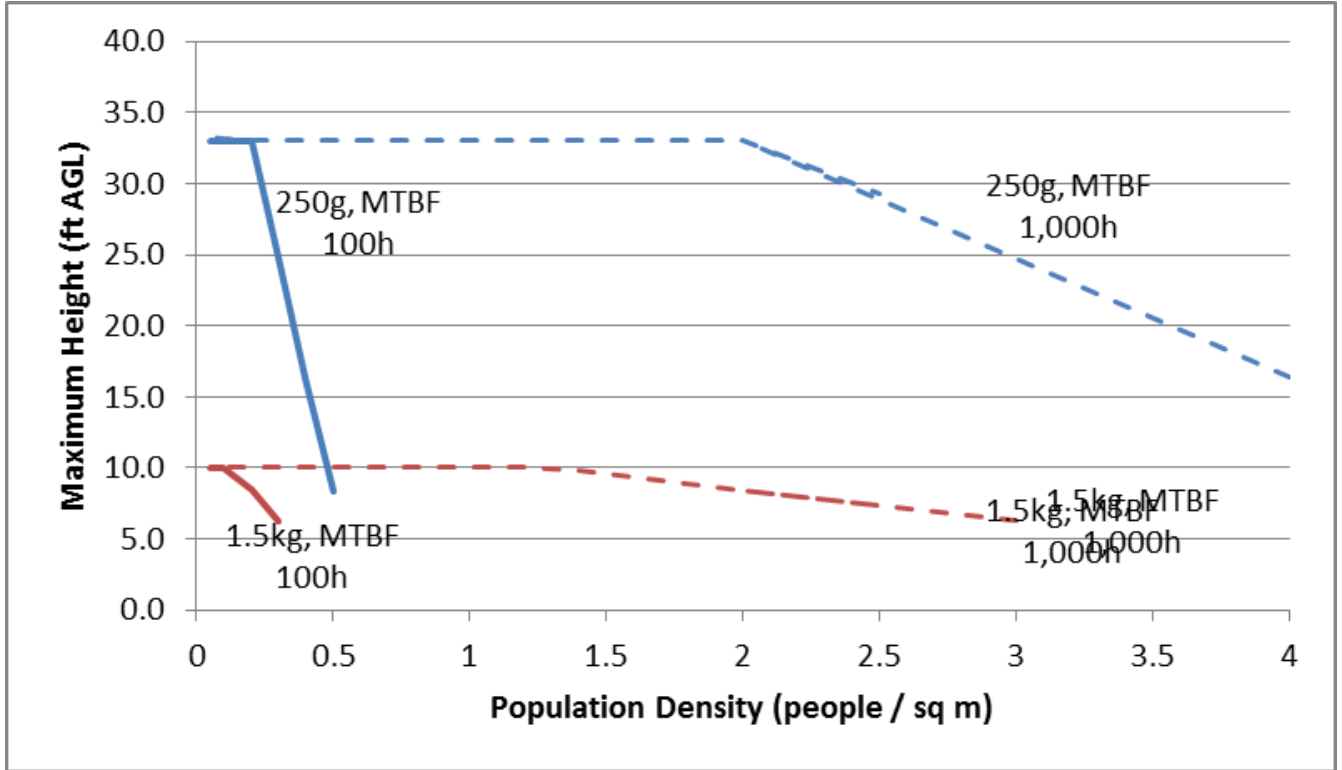

Figure 8. Maximum Allowable Height by Aircraft Size and Population Density, US Normalized Social Cost, Alternative MTBF Assumptions. Source: Table 8 (appendix).

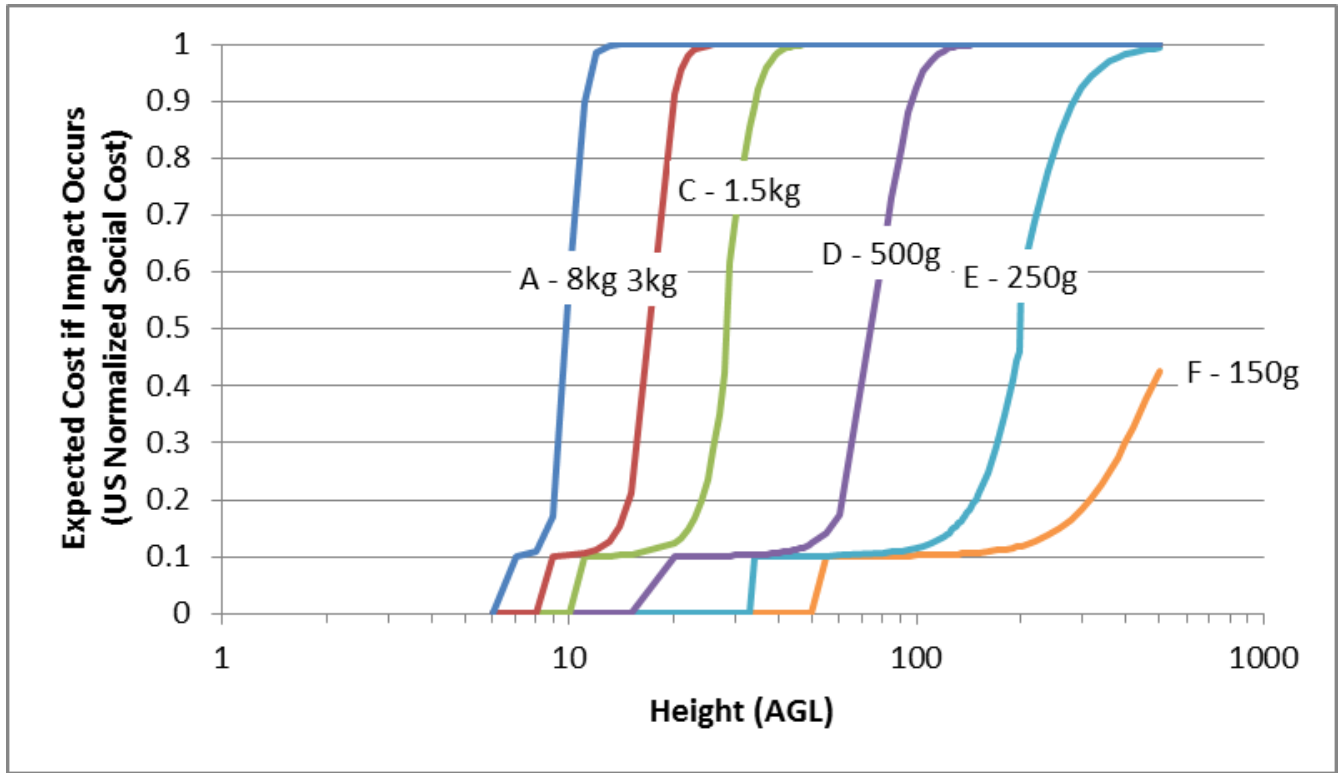

Figure 9. Expected Cost if Impact Occurs, US Normalized Social Cost. Source: Table 9 in the appendix provides values to 100ft AGL. 


\section{Conclusion}

The Human Harm Model quantifies the harm that can arise when a person is hit by a multi-rotor unmanned aircraft that has experienced some form of failure, and falls on people below. With a safety goal based on the ground fatality rate for existing manned aircraft, the analysis indicates that there should be significant restrictions on flying over people, including maximum heights that are quite restrictive compared to the maximum of 400ft AGL currently allowed. Flying over people is also only safe at low population densities. Unmanned aircraft in excess of $1.5 \mathrm{~kg}$ should not be flown over a crowd of people at any density.

Parachutes are highly effective at increasing the maximum allowable height for most unmanned aircraft, increasing the maximums from tens of feet to $400 \mathrm{ft}$ AGL. Increasing the reliability of unmanned aircraft enables them to fly above much greater densities of people. Manufacturers could potentially conduct testing programs to quantify the failure rate, but many hundreds of hours of testing might be required for this. Alternatively, registered UAS operators might be encouraged to report all crashes and hours flown. It is recommended that additional restrictions be added to New Zealand's Civil Aviation Rules, restricting the range of circumstances in which an unmanned aircraft can be flown over people. The New Zealand CAA's stated intention to require unmanned aircraft to have a parachute to fly over people is appropriate in some instances, but the model indicates that a parachute does not appreciably alter risk for the heavier aircraft; nor does it increase the population densities over which an aircraft can fly. Flying over a high density of people requires a UAS with a high level of reliability.

The model also indicates that the recommendation of the Micro UAS ARC to allow unmanned aircraft of $250 \mathrm{~g}$ or less to fly over people without restrictions is unsafe. This recommendation appears to follow from assumptions that do not reflect likely scenarios of actually flying over people (but are realistic for a scenario of traversing across a populated area, with trees, buildings, and most people sheltered).

Finally, it is important to note that optimal social cost will require more restrictions in addition to maximum height above people. This paper, for example, does not address the appropriate horizontal distance between an unmanned aircraft and a person. 


\section{Further Development}

There are a number of areas in which this model can be applied to provide more accurate predictions of the range of potential injury outcomes. A refined model could separately identify impacts to a person's shoulder region from impacts to the head, and potentially allow for glancing blows (such as those reported in Molinet, 2015). An obvious additional area for development is in the injuries from loss-of-control incidents that might occur when the unmanned aircraft is close to people and horizontal impacts may occur. Such a model would also need to include estimates of the injuries that might occur from people being cut by the spinning propellers. Refined estimates of the cross-sectional surface area and coefficient of drag would improve the accuracy of the estimates, but might not qualitatively affect the results. A significant gap in the data is that of the applicable failure rate. With no data on hours flown, and no reliable data on the number of failures that occur, there is currently no way to accurately estimate this rate. 


\section{References}

Baby killed by remote control helicopter. (2013, March 22). Borneo Post. Retrieved from http://www.theborneopost.com/2013/03/22/baby-killed-byremote-control-helicopter/

Ball, J.A., Knott, M., and Burke, D. (2012, June 6). Crash Lethality Model. Technical Report, No. NAWCADPAX/TR-2012/196, Naval Air Warfare Center Aircraft Division, Patuxent River, Maryland. Retrieved from http://oai.dtic.mil/oai/oai?verb=getRecord\&metadataPrefix $=$ html\&identifier $=$ ADB382358

CAA. (2015, July 27). Advisory Circular AC102-1: Unmanned Aircraft Operator Certification. Civil Aviation Authority, Rev 0.

CASA. (2013, December 23). Human injury model for small unmanned aircraft impacts. Civil Aviation Safety Authority/Monash University. Retrieved from https://www.casa.gov.au/sites/g/files/net351/f/_assets/main/airworth/papers/h uman-injury-model-small-unmanned-aircraft-impacts.pdf

Centers for Disease Control and Prevention. (2016, Feburary 8). Injury Prevention \& Control: Traumatic Brain Injury \& Concussion: Severe TBI. Retrieved from http://www.cdc.gov/traumaticbraininjury/severe.html

Chen, A., Bushmeneva, K., Zagorski, B., Colantonio, A., Parsons, D., and Wodchis, W.P. (2012). Direct cost associated with acquired brain injury in Ontario. BMC Neurology, 12, 76. http://dx.doi.org/10.1186/1471-2377-12-76

Civil Aviation Act (1990). Public Act 1990 No. 98, New Zealand Statutes, reprint as at 1 March 2016. Retrieved from www.legislation.govt.nz/act/public/1990/0098/latest/096be8ed81299964.pdf

Civil Aviation Safety Regulations (1998). Statutory Rules No. 237, made under the Civil Aviation Act 1998, compilation date 5 March 2016. Retrieved from https://www.legislation.gov.au/Details/F2016C00234/Html/Volume_3

Clothier, R.A., and Walker, R.A. (2006). Determination and Evaluation of UAS Safety Objectives. Proceedings 21st International Unmanned Air Vehicle Systems Conference, pp. 18.1-18.16. 
Cooter, R., Kornhauser, L., and Lane, D. (1979). Liability rules, limited information, and the role of precedent. Bell Journal of Economics, 10, 366373. Retrieved from http://works.bepress.com/robert_cooter/33/

Crowe, C.T., Elger, D.F., Williams, B.C., and Roberson, J.A. (2009). Engineering Fluid Mechanics, $\left(9^{\text {th }}\right.$ ed.). Hoboken, New Jersey: John Wiley \& Sons

Curtis, M. (2013, July 11). Operator of remote control helicopter dies. The Local.ch. Retrieved from http://www.thelocal.ch/20130711/remote-controlhelicopter-kills-operator-in-lucerne

Dalamagkidis, K., Valavanis, K.P., and Piegl, L.A. (2008). Evaluating the Risk of Unmanned Aircraft Ground Impacts. $16^{\text {th }}$ Mediterranean Conference on Control and Automation, June 25-27, 2008, IEEE, pp.709-716.

Davis, J. (2011). The (Common) Laws of Man Over Vehicles Unmanned:

Comment by Emeritus Professor Jim Davis. JLIS Special Edition: The Law of Unmanned Vehicles, 21(2), 166-179.

http://dx.doi.org/10.5778/JLIS.2011.21.Davis.1

DJI. (2015). DJI DROPSAFE User Manual, v1.2. Retrieved from http://dl.djicdn.com/downloads/dropsafe/en/DJI_Dropsafe_User_Manual_v1. 2_en.pdf

Falling drone knocks woman out at Seattle pride parade. (2015, June 30). CBS News. Retrieved from http://www.cbsnews.com/news/falling-drone-knockswoman-out-seattle-pride-parade/

Federal Aviation Administration. (2015, December 16). Registration and Marking Requirements for Small Unmanned Aircraft, Interim Final Rule 80 FR 78593. Retrieved from https://federalregister.gov/a/2015-31750

Fowles, G.R. and Cassiday, G.L. (2005). Analytical Mechanics, $\left(7^{\text {th }}\right.$ ed. International Student Edition). Pacific Grove, California: Thomson Brookes/Cole.

FruityChutes.com. (2016). Ultimate Parachute System for all Drones, Multicopters and UAS. Retrieved from https://fruitychutes.com/UAS_rpv_drone_recovery_parachutes.htm 
Grubb, B. (2014, April 7). 'River of blood' after drone 'hits' Australian athlete. Sydney Morning Herald. Retrieved from http://www.smh.com.au/technology/technology-news/river-of-blood-afterdrone-hits-australian-athlete-20140407-zqruh.html

Heli pilot killed in Japan. (2013, July 18). HeliFreak.com. Retrieved from http://www.helifreak.com/showthread.php?t=549389

Henderson, J. (2010). Lethality Criteria for Debris Generated from Accidental Explosions. UK Ministry of Defence. Retrieved from www.dtic.mil/cgibin/GetTRDoc?AD=ADA532158

Henry, J. (2015, September 15). Falling drone injures 11-month old near Pasadena City Hall. Pasadena Star-News. Retrieved from http://www.pasadenastarnews.com/general-news/20150915/falling-droneinjures-11-month-old-near-pasadena-city-hall

Jakubiak, J.M. (1997). Maintaining Air Safety at Less Cost: A Plan for Replacing FAA Safety Regulations with Strict Liability. Cornell Journal of Law and Public Policy, 6(2), 421-440. Retrieved from http://scholarship.law.cornell.edu/cjlpp/vol6/iss $2 / 6$

Kolstad, C.D., Ulen, T.S., and Johnson, G.V. (1990). Ex Post Liability for Harm vs. Ex Ante Safety Regulation: Substitutes or Complements? American Economic Review, 80(4), 888-901. Retrieved from http://www.jstor.org/stable/2006714

Li, D.K. (2015, October 8). Drone bursts into flames on quiet Hamptons street. New York Post. Retrieved from http://nypost.com/2015/10/08/drone-burstsinto-flames-on-quiet-hamptons-street/

Man killed by Model Helicopter. (2003, November 3). RC Groups.com. Retrieved from http://www.rcgroups.com/forums/showthread.php?t=165680

Marks, P. (2012, May 18). GPS loss kicked off fatal drone crash. New Scientist. Retrieved from http://www.newscientist.com/blogs/onepercent/2012/05/gpsloss-kicked-off-fatal-dron.html 
Mattei, T.A., Bond, B.J., Goulart, C.R., Sloffer, C.A., Morris, M.J., and Lin, J.J. (2012). Performance analysis of the protective effects of bicycle helmets during impact and crush tests in pediatric skull models Laboratory investigation. Journal of Neurosurgery: Pediatrics, 10(6), 490-497. http://dx.doi.org/10.3171/2012.8.PEDS12116

Ministry of Transport (2016) The Social Cost of Road Crashes and Injuries: 2015 Update. Retrieved from http://www.transport.govt.nz/assets/Uploads/Research/Documents/Socialcost-of-road-crashes-and-injuries-2015-update.pdf

Molinet, J. (2015, May 26). Drone crashes into crowd at Memorial Day parade in Marblehead, Mass. New York Daily News. Retrieved from http://www.nydailynews.com/news/national/drone-crashes-crowd-memorialday-parade-mass-article-1.2235360

Mortimer, G. (2012, October 27). Multirotor hits skyscraper and burns, Auckland NZ. sUASNews.com. Retrieved from http://www.suasnews.com/2012/10/multirotor-hits-skyscraper-and-burnsdowntown-auckland-nz/

National Transportation Safety Board. (n.d.). 2014 preliminary aviation statistics. Retrieved from http://www.ntsb.gov/investigations/data/pages/aviation_stats.aspx.

NFL. (2015). 2015 NFL Rulebook. Retrieved from http://operations.nfl.com/therules/2015-nfl-rulebook/

Oberhagemann, D. (2012). Static and Dynamic Crowd Densities at Major Public Events, Vereinigung zur FÄrderung des Deutschen Brandschutzes e. V. (vfdb), German Fire Protection Association, Technical-scientific advisory board (TWB), Department 13, Technical Report vfdb TB 13-01. Retrieved from http://www.vfdb.de/download/TB_13_01_Crowd_densities.pdf

Opale Paramodels. (n.d.). Parachutes - UAS Drones. Retrieved from http://www.opale-paramodels.com/index.php/en/shopopaleparamodels/rescue-systems 
Payne, A.R. and Patel, S. (2001). Occupant Protection \& Egress In Rail Systems project (OPERAS): Injury Mechanisms \& Injury Criteria. MIRA, UK.

Retrieved from

http://www.eurailsafe.net/subsites/operas/HTML/Section3/Section3.3frm.htm

Pezzullo, L. and Crook, A. (2006). The economic and social costs of occupational disease and injury in New Zealand: NOHSAC Technical Report 4, Wellington, New Zealand:Access Economics. Retrieved from http://ipru3.otago.ac.nz/ipru/ReportsPDFs/OR058.pdf

Polinder, S., W.J. Meerding, M.E. van Baar, H. Toet, S. Mulder, E.F. van Beeck, and EUROCOST reference group (2005) "Cost Estimation of Injury-Related Hospital Admissions in 10 European Countries", Journal of TRAUMA Injury, Infection, and Critical Care, 59(6), 1283-1291. Retrieved from http://www.euroipn.net/cerepri/modules/Publications/publ_files/JOTRAUM A\%20Polinder.pdf.

Raymond, D., Van Ee, C., Crawford, G., and Bir, C. (2009). Tolerance of the skull to blunt ballistic temporo-parietal impact. Journal of Biomechanics, 42(2009), 2479-2485. http://dx.doi.org/10.1016/j.jbiomech.2009.07.018

Sapsted, D. (2003, November 18). Girl, 14, killed by model plane after nearmisses. The Telegraph. Retrieved from http://www.telegraph.co.uk/news/uknews/1447013/Girl-14-killed-by-modelplane-after-near-misses.html

Sharkey, E.J., Cassidy, M., Brady, J., Gilchrist, M.D., NicDaeid, N. (2012). Investigation of the force associated with the formation of lacerations and skull fractures. International Journal of Legal Medicine, 126(6), 835-844. http://dx.doi.org/10.1007/s00414-011-0608-z

Shavell, S. (1980). Strict Liability versus Negligence. Journal of Legal Studies, 9(1), 1-25. http://dx.doi.org/10.1086/467626

Shavell, S. (1984). Liability for Harm versus Regulation of Safety. Journal of Legal Studies, 13(2), 357-374. http://dx.doi.org/10.1086/467745

Shavell, S. (1986). The Judgement Proof Problem. International Review of Law and Economics, 6, 45-48. 
Skobir, Z. and Magister, T. (2011). Assessment of a Light Unmanned Aircraft Ground Impact Emergency. Promet - Traffic \& Transportation, 23(2), 97104. Retrieved from http://hrcak.srce.hr/file/122035

Still, G.K. (2013, October 4). Visualising crowd density. Crowd Safety and Risk Analysis. Retrieved from http://www.gkstill.com/Support/crowddensity/CrowdDensity-2.html

Swisdak, M.M, Tatom, J.W., and Hoing, C.A. (2007, October 22). Procedures For The Collection, Analysis and Interpretation Of Explosion-Produced Debris-Revision 1, Technical Paper DDESB TP 21, Department Of Defense Explosives Safety Board. Retrieved from http://www.dtic.mil/dtic/tr/fulltext/u2/a474098.pdf

Taillier, S., ABC News (2014, April 8). Triathlete injured as drone filming race falls to ground, $A B C$ News. Retrieved from http://www.abc.net.au/news/2014-04-07/triathlete-injured-as-drone-filmingrace-drops-to-ground/5371658

UAS Task Force. (2015, November 21). Task Force Recommendations Final Report, Unmanned Aircraft Systems (UAS) Registration Task Force (RTF) Aviation Rulemaking Committee (ARC). Retrieved from https://www.faa.gov/uas/publications/media/RTFARCFinalReport_11-2115.pdf

Waldstein, D. (2015. September 3). Drone Crash Interrupts Match. New York Times. Retrieved from http://www.nytimes.com/live/us-open-results/dronecrash-interrupts-match/

Williams, G. (2015, Febuary 13). Drone owner warned after crashing it into Queenstown hotel. New Zealand Herald. Retrieved from http://www.nzherald.co.nz/nz/news/article.cfm?c_id=1\&objectid=11401151

Yoganandan, N., Pintar, F.A., Sances Jr., A., Walsh, P.R., Ewing, C.L., Thomas, D.J., and Snyder, R.G. (1995) Biomechanics of Skull Fracture. Journal of Neurotrauma, 12(4), 659-668. http://dx.doi.org/10.1089/neu.1995.12.659 
Zaloshnja, E., Miller, T., Romano, E., and Spicer, R. (2004). Crash costs by body part injured, fracture involvement, and threat-to-life severity, United States, 2000. Accident Analysis \& Prevention, 36(3):415-427. http://dx.doi.org/10.1016/S0001-4575(03)00035-6

Zennie, M. (2013, September 5). Horror as remote-control helicopter stunt pilot, 19, partially-decapitates himself with his aircraft after he lost control. Daily Mail. Retrieved from http://www.dailymail.co.uk/news/article2413231/Roman-Pirozek-Jr-Man-decapitates-remote-control-helicopter.html 


\section{Appendix}

Table 7

Fatalities and Fatality Rates, 1995 through 2014, U.S. General Aviation.

\begin{tabular}{|c|c|c|c|c|c|c|}
\hline \multirow[b]{2}{*}{ Year } & \multicolumn{3}{|c|}{ Fatalities } & \multirow{2}{*}{$\begin{array}{l}\text { Flight } \\
\text { Hours }\end{array}$} & \multicolumn{2}{|c|}{ Fatality Rate } \\
\hline & Total & Aboard & $\begin{array}{c}\text { Not } \\
\text { Aboard }\end{array}$ & & Total & $\begin{array}{c}\text { Not } \\
\text { Aboard }\end{array}$ \\
\hline 1995 & 734 & 727 & 7 & $24,906,000$ & $2.95 \mathrm{E}-05$ & $2.81 \mathrm{E}-07$ \\
\hline 1996 & 636 & 619 & 17 & $24,881,000$ & $2.56 \mathrm{E}-05$ & $6.83 \mathrm{E}-07$ \\
\hline 1997 & 631 & 625 & 6 & $25,591,000$ & $2.47 \mathrm{E}-05$ & $2.34 \mathrm{E}-07$ \\
\hline 1998 & 624 & 618 & 6 & $25,518,000$ & $2.45 \mathrm{E}-05$ & $2.35 \mathrm{E}-07$ \\
\hline 1999 & 621 & 615 & 6 & $29,246,000$ & $2.12 \mathrm{E}-05$ & $2.05 \mathrm{E}-07$ \\
\hline 2000 & 596 & 585 & 11 & $27,838,000$ & $2.14 \mathrm{E}-05$ & $3.95 \mathrm{E}-07$ \\
\hline 2001 & 562 & 558 & 4 & $25,431,000$ & $2.21 \mathrm{E}-05$ & $1.57 \mathrm{E}-07$ \\
\hline 2002 & 581 & 575 & 6 & $25,545,000$ & $2.27 \mathrm{E}-05$ & $2.35 \mathrm{E}-07$ \\
\hline 2003 & 633 & 630 & 3 & $25,998,000$ & $2.43 \mathrm{E}-05$ & $1.15 \mathrm{E}-07$ \\
\hline 2004 & 559 & 559 & 0 & $24,888,000$ & $2.25 \mathrm{E}-05$ & 0 \\
\hline 2005 & 563 & 558 & 5 & $23,168,000$ & $2.43 \mathrm{E}-05$ & $2.16 \mathrm{E}-07$ \\
\hline 2006 [*] & 706 & 547 & 159 & $23,963,000$ & $2.95 \mathrm{E}-05$ & $6.64 \mathrm{E}-06$ \\
\hline 2007 & 496 & 491 & 5 & $23,819,000$ & $2.08 \mathrm{E}-05$ & $2.1 \mathrm{E}-07$ \\
\hline 2008 & 496 & 487 & 9 & $22,805,000$ & $2.17 \mathrm{E}-05$ & $3.95 \mathrm{E}-07$ \\
\hline 2009 & 479 & 470 & 9 & $20,862,000$ & $2.30 \mathrm{E}-05$ & $4.31 \mathrm{E}-07$ \\
\hline 2010 & 458 & 455 & 3 & $21,688,000$ & $2.11 \mathrm{E}-05$ & $1.38 \mathrm{E}-07$ \\
\hline 2011 & 452 & 441 & 11 & - & - & - \\
\hline 2012 & 437 & 437 & 0 & $20,881,000$ & $2.09 \mathrm{E}-05$ & 0 \\
\hline 2013 & 391 & 386 & 5 & $19,492,000$ & $2.01 \mathrm{E}-05$ & $2.57 \mathrm{E}-07$ \\
\hline 2014 & 419 & 410 & 9 & $18,103,000$ & $2.31 \mathrm{E}-05$ & 4.97E-07 \\
\hline Total excl 2011 & 10,622 & 10,352 & 270 & $454,623,000$ & $2.34 \mathrm{E}-05$ & $5.94 \mathrm{E}-07$ \\
\hline
\end{tabular}

Source: Fatalities for "Total" and "Aboard" and "Flight Hours" from National Transportation Safety Board (n.d.). Fatalities for "Not Aboard" are calculated as the difference between "Total" and "Aboard".

Note: [*] The 706 Total Fatalities for 2006 includes the 154 people killed aboard a non-US registered Boeing 737 aircraft when it collided with a US-registered Embraer Legacy business jet over the Brazilian Amazon jungle. These 154 fatalities were not aboard a US-registered aircraft, so are included in the "Not Aboard" total. If they are excluded then the total "Not Aboard" for the entire period excluding 2011 is 105 , and the fatality rate is $2.31 \mathrm{E}-07$. 
Table 8

Maximum Allowable Height (ft above ground level) by Scenario, Aircraft Size, and Population Density.

\begin{tabular}{|c|c|c|c|c|c|c|c|c|c|c|c|c|c|c|c|c|c|}
\hline \multirow{2}{*}{$\begin{array}{l}\text { Aircraft } \\
\text { Size }\end{array}$} & \multicolumn{17}{|c|}{ Population Density (people/m²) } \\
\hline & 4 & 3 & 2.5 & 2 & 1.8 & 1.6 & 1.4 & 1.2 & 1 & 0.8 & 0.6 & 0.5 & $\mathbf{0 . 4}$ & 0.3 & 0.2 & $\mathbf{0 . 1}$ & 0.05 \\
\hline \multicolumn{18}{|c|}{ New Zealand Normalized Social Cost } \\
\hline$F-150 g$ & --- & --- & --- & --- & --- & --- & --- & --- & --- & 17.3 & 29.1 & 36.1 & 44.3 & 50.0 & 50.0 & 50.1 & 50.3 \\
\hline$E-250 g$ & --- & --- & --- & --- & --- & --- & --- & --- & --- & --- & 13.8 & 18.0 & 23.2 & 29.2 & 33.0 & 33.0 & 33.0 \\
\hline D - 500g & --- & --- & --- & --- & --- & --- & --- & --- & --- & --- & --- & 11.9 & 14.3 & 15.0 & 15.0 & 15.1 & 15.3 \\
\hline $\mathrm{C}-1.5 \mathrm{~kg}$ & --- & --- & --- & --- & --- & --- & --- & --- & --- & --- & --- & --- & --- & --- & --- & 10.0 & 10.0 \\
\hline B $-3 \mathrm{~kg}$ & --- & --- & --- & --- & --- & --- & --- & --- & --- & --- & --- & --- & --- & --- & --- & --- & --- \\
\hline A - 8kg & --- & --- & --- & --- & --- & --- & --- & --- & --- & --- & --- & --- & --- & --- & --- & --- & --- \\
\hline
\end{tabular}

\section{United States Normalized Social Cost}

\begin{tabular}{|c|c|c|c|c|c|c|c|c|c|c|c|c|c|c|c|c|c|}
\hline$F-150 g$ & --- & --- & --- & --- & --- & --- & --- & --- & --- & --- & 14.2 & 24.9 & 36.0 & 48.8 & 50.0 & 50.1 & 50.2 \\
\hline$E-250 g$ & --- & -- & -- & --- & --- & --- & --- & --- & --- & --- & --- & 8.4 & 16.3 & 24.7 & 33.0 & 33.0 & 33.0 \\
\hline D - 500g & --- & --- & --- & --- & --- & --- & --- & --- & --- & --- & --- & 7.1 & 11.1 & 15.0 & 15.0 & 15.1 & 15.1 \\
\hline $\mathrm{C}-1.5 \mathrm{~kg}$ & --- & --- & --- & --- & --- & --- & --- & --- & --- & --- & --- & --- & --- & 6.3 & 8.4 & 10.0 & 10.0 \\
\hline B - $3 \mathrm{~kg}$ & --- & --- & --- & --- & --- & --- & --- & --- & --- & --- & --- & --- & --- & --- & 6.1 & 7.6 & 8.0 \\
\hline$A-8 k g$ & --- & --- & --- & --- & --- & --- & --- & --- & --- & --- & --- & --- & --- & --- & --- & 6.0 & 6.0 \\
\hline
\end{tabular}




\begin{tabular}{|c|c|c|c|c|c|c|c|c|c|c|c|c|c|c|c|c|c|}
\hline \multirow{2}{*}{$\begin{array}{l}\text { Aircraft } \\
\text { Size }\end{array}$} & \multicolumn{17}{|c|}{ Population Density (people/m²) } \\
\hline & 4 & 3 & 2.5 & 2 & 1.8 & 1.6 & 1.4 & 1.2 & 1 & 0.8 & 0.6 & 0.5 & 0.4 & 0.3 & 0.2 & 0.1 & 0.05 \\
\hline \multicolumn{18}{|c|}{ United States Normalized Social Cost, Safety Goal $=5 \times 10-5$} \\
\hline F - $150 \mathrm{~g}$ & $\begin{array}{c}50 . \\
2\end{array}$ & $\begin{array}{c}50 . \\
2\end{array}$ & $\begin{array}{c}50 . \\
3\end{array}$ & $\begin{array}{c}50 . \\
4\end{array}$ & $\begin{array}{c}50 . \\
4\end{array}$ & $\begin{array}{c}50 . \\
5\end{array}$ & $\begin{array}{c}50 . \\
6\end{array}$ & $\begin{array}{c}50 . \\
7\end{array}$ & $\begin{array}{c}50 . \\
8\end{array}$ & 51.0 & 51.3 & 51.6 & 52.0 & 52.7 & 54.1 & $\begin{array}{c}280 . \\
0\end{array}$ & $\begin{array}{c}424 . \\
0\end{array}$ \\
\hline$E-250 g$ & $\begin{array}{c}33 . \\
0\end{array}$ & $\begin{array}{c}33 . \\
0\end{array}$ & $\begin{array}{c}33 . \\
0\end{array}$ & $\begin{array}{c}33 . \\
1\end{array}$ & $\begin{array}{c}33 . \\
1\end{array}$ & $\begin{array}{c}33 . \\
1\end{array}$ & $\begin{array}{c}33 . \\
1\end{array}$ & $\begin{array}{c}33 . \\
1\end{array}$ & $\begin{array}{c}33 . \\
1\end{array}$ & 33.2 & 33.2 & 33.3 & 33.3 & 33.4 & 33.6 & $\begin{array}{c}115 . \\
2\end{array}$ & $\begin{array}{c}162 . \\
7\end{array}$ \\
\hline D - 500g & $\begin{array}{c}15 \\
1\end{array}$ & $\begin{array}{c}15 \\
2\end{array}$ & $\begin{array}{c}15 \\
2\end{array}$ & $\begin{array}{c}15 \\
3\end{array}$ & $\begin{array}{c}15 . \\
3\end{array}$ & $\begin{array}{c}15 \\
4\end{array}$ & $\begin{array}{c}15 \\
4\end{array}$ & $\begin{array}{c}15 \\
5\end{array}$ & $\begin{array}{c}15 . \\
6\end{array}$ & 15.8 & 16.1 & 16.3 & 16.6 & 17.1 & 18.2 & 51.8 & 63.8 \\
\hline $\mathrm{C}-1.5 \mathrm{~kg}$ & $\begin{array}{c}10 . \\
0\end{array}$ & $\begin{array}{c}10 . \\
0\end{array}$ & $\begin{array}{c}10 . \\
0\end{array}$ & $\begin{array}{c}10 . \\
0\end{array}$ & $\begin{array}{c}10 . \\
0\end{array}$ & $\begin{array}{c}10 . \\
0\end{array}$ & $\begin{array}{c}10 . \\
0\end{array}$ & $\begin{array}{c}10 . \\
1\end{array}$ & $\begin{array}{c}10 . \\
1\end{array}$ & 10.1 & 10.1 & 10.2 & 10.2 & 10.3 & 10.4 & 10.8 & 22.4 \\
\hline $\mathrm{B}-3 \mathrm{~kg}$ & 8.0 & 8.0 & 8.0 & 8.0 & 8.0 & 8.0 & 8.0 & 8.0 & 8.0 & 8.1 & 8.1 & 8.1 & 8.1 & 8.2 & 8.3 & 8.5 & 11.0 \\
\hline A - $8 \mathrm{~kg}$ & 6.0 & 6.0 & 6.0 & 6.0 & 6.0 & 6.0 & 6.0 & 6.0 & 6.0 & 6.0 & 6.0 & 6.1 & 6.1 & 6.1 & 6.1 & 6.3 & 6.6 \\
\hline \multicolumn{18}{|c|}{ New Zealand Normalized Social Cost, with Parachute } \\
\hline $\mathrm{F}-150 \mathrm{~g}$ & --- & --- & --- & --- & --- & --- & --- & --- & 7.0 & $\begin{array}{c}400 . \\
0\end{array}$ & $\begin{array}{c}400 . \\
0\end{array}$ & $\begin{array}{c}400 . \\
0\end{array}$ & $\begin{array}{c}400 . \\
0\end{array}$ & $\begin{array}{c}400 . \\
0\end{array}$ & 400.0 & $\begin{array}{c}400 . \\
0\end{array}$ & $\begin{array}{c}400 . \\
0\end{array}$ \\
\hline E - 250g & --- & --- & --- & --- & --- & --- & --- & --- & --- & --- & $\begin{array}{c}400 . \\
0\end{array}$ & $\begin{array}{c}400 . \\
0\end{array}$ & $\begin{array}{c}400 . \\
0\end{array}$ & $\begin{array}{c}400 . \\
0\end{array}$ & 400.0 & $\begin{array}{c}400 . \\
0\end{array}$ & $\begin{array}{c}400 . \\
0\end{array}$ \\
\hline D - 500g & --- & --- & --- & --- & --- & --- & --- & --- & --- & --- & $\begin{array}{c}400 . \\
0\end{array}$ & $\begin{array}{c}400 . \\
0\end{array}$ & $\begin{array}{c}400 . \\
0\end{array}$ & $\begin{array}{c}400 . \\
0\end{array}$ & 400.0 & $\begin{array}{c}400 . \\
0\end{array}$ & $\begin{array}{c}400 . \\
0\end{array}$ \\
\hline $\mathrm{C}-1.5 \mathrm{~kg}$ & --- & --- & --- & --- & --- & --- & --- & --- & --- & --- & --- & --- & 6.7 & 7.9 & 9.6 & $\begin{array}{c}400 . \\
0\end{array}$ & $\begin{array}{c}400 . \\
0\end{array}$ \\
\hline B - 3kg & --- & --- & --- & -- & --- & -- & --- & -- & --- & --- & --- & --- & --- & 6.0 & 6.8 & 8.0 & 8.0 \\
\hline $\mathrm{A}-8 \mathrm{~kg}$ & --- & --- & --- & --- & --- & --- & --- & --- & --- & --- & --- & --- & --- & --- & --- & 6.0 & 6.0 \\
\hline
\end{tabular}




\begin{tabular}{|c|c|c|c|c|c|c|c|c|c|c|c|c|c|c|c|c|c|}
\hline \multirow{2}{*}{$\begin{array}{l}\text { Aircraft } \\
\text { Size }\end{array}$} & \multicolumn{17}{|c|}{ Population Density (people/m²) } \\
\hline & 4 & 3 & 2.5 & 2 & 1.8 & 1.6 & 1.4 & 1.2 & 1 & 0.8 & 0.6 & 0.5 & 0.4 & 0.3 & 0.2 & 0.1 & 0.05 \\
\hline \multicolumn{18}{|c|}{ United States Normalized Social Cost, MTBF 1 in 1000} \\
\hline $\mathrm{F}-150 \mathrm{~g}$ & $\begin{array}{c}36 . \\
0\end{array}$ & $\begin{array}{c}48 . \\
8\end{array}$ & $\begin{array}{c}50 . \\
0\end{array}$ & $\begin{array}{c}50 . \\
0\end{array}$ & $\begin{array}{c}50 . \\
0\end{array}$ & $\begin{array}{c}50 . \\
0\end{array}$ & $\begin{array}{c}50 . \\
0\end{array}$ & $\begin{array}{c}50 . \\
0\end{array}$ & $\begin{array}{c}50 . \\
1\end{array}$ & 50.1 & 50.1 & 50.2 & 50.2 & 50.3 & 50.5 & 51.0 & 52.0 \\
\hline$E-250 g$ & $\begin{array}{c}16 \\
3\end{array}$ & $\begin{array}{c}24 . \\
7\end{array}$ & $\begin{array}{c}29 . \\
3\end{array}$ & $\begin{array}{c}33 . \\
0\end{array}$ & $\begin{array}{c}33 . \\
0\end{array}$ & $\begin{array}{c}33 . \\
0\end{array}$ & $\begin{array}{c}33 . \\
0\end{array}$ & $\begin{array}{c}33 . \\
0\end{array}$ & $\begin{array}{c}33 . \\
0\end{array}$ & 33.0 & 33.0 & 33.0 & 33.0 & 33.0 & 33.1 & 33.1 & 33.3 \\
\hline D - 500g & $\begin{array}{c}11 . \\
1\end{array}$ & $\begin{array}{c}15 . \\
0\end{array}$ & $\begin{array}{c}15 . \\
0\end{array}$ & $\begin{array}{c}15 . \\
0\end{array}$ & $\begin{array}{c}15 . \\
0\end{array}$ & $\begin{array}{c}15 . \\
0\end{array}$ & $\begin{array}{c}15 . \\
0\end{array}$ & $\begin{array}{c}15 . \\
0\end{array}$ & $\begin{array}{c}15 . \\
1\end{array}$ & 15.1 & 15.1 & 15.1 & 15.2 & 15.2 & 15.4 & 15.8 & 16.5 \\
\hline $\mathrm{C}-1.5 \mathrm{~kg}$ & --- & 6.3 & 7.4 & 8.4 & 8.9 & 9.3 & 9.8 & $\begin{array}{c}10 . \\
0\end{array}$ & $\begin{array}{c}10 . \\
0\end{array}$ & 10.0 & 10.0 & 10.0 & 10.0 & 10.0 & 10.0 & 10.1 & 10.2 \\
\hline $\mathrm{B}-3 \mathrm{~kg}$ & --- & --- & --- & 6.1 & 6.3 & 6.7 & 7.0 & 7.3 & 7.6 & 8.0 & 8.0 & 8.0 & 8.0 & 8.0 & 8.0 & 8.1 & 8.1 \\
\hline $\mathrm{A}-8 \mathrm{~kg}$ & --- & --- & --- & --- & --- & --- & --- & --- & 6.0 & 6.0 & 6.0 & 6.0 & 6.0 & 6.0 & 6.0 & 6.0 & 6.1 \\
\hline
\end{tabular}


Table 9

Expected Cost Conditional Upon Impact Occurring, heights to 100ft AGL, US Normalized Social Cost.

\begin{tabular}{|c|c|c|c|c|c|c|}
\hline \multirow{2}{*}{$\begin{array}{c}\text { Height } \\
\text { (ft AGL) }\end{array}$} & \multicolumn{6}{|c|}{ Aircraft Size } \\
\hline & $F-150 g$ & E - 250g & D - 500g & $\mathrm{C}-1.5 \mathrm{~kg}$ & B - 3kg & A - 8kg \\
\hline 6 & 0.0003 & 0.0003 & 0.0003 & 0.0003 & 0.0003 & 0.0003 \\
\hline 7 & 0.0003 & 0.0003 & 0.0003 & 0.0004 & 0.0004 & 0.1010 \\
\hline 8 & 0.0003 & 0.0003 & 0.0003 & 0.0004 & 0.0007 & 0.1088 \\
\hline 9 & 0.0003 & 0.0003 & 0.0003 & 0.0005 & 0.1011 & 0.1695 \\
\hline 10 & 0.0003 & 0.0003 & 0.0004 & 0.0007 & 0.1024 & 0.5896 \\
\hline 11 & 0.0003 & 0.0003 & 0.0004 & 0.1007 & 0.1053 & 0.8989 \\
\hline 12 & 0.0003 & 0.0003 & 0.0004 & 0.1010 & 0.1117 & 0.9861 \\
\hline 13 & 0.0003 & 0.0004 & 0.0004 & 0.1015 & 0.1254 & 0.9983 \\
\hline 14 & 0.0003 & 0.0004 & 0.0005 & 0.1022 & 0.1541 & 0.9998 \\
\hline 15 & 0.0003 & 0.0004 & 0.0005 & 0.1033 & 0.2111 & 1.0000 \\
\hline 20 & 0.0004 & 0.0004 & 0.1006 & 0.1227 & 0.9132 & 1.0000 \\
\hline 21 & 0.0004 & 0.0005 & 0.1006 & 0.1330 & 0.9572 & 1.0000 \\
\hline 22 & 0.0004 & 0.0005 & 0.1007 & 0.1479 & 0.9796 & 1.0000 \\
\hline 23 & 0.0004 & 0.0005 & 0.1008 & 0.1687 & 0.9904 & 1.0000 \\
\hline 24 & 0.0004 & 0.0005 & 0.1009 & 0.1976 & 0.9955 & 1.0000 \\
\hline 25 & 0.0004 & 0.0005 & 0.1011 & 0.2364 & 0.9979 & 1.0000 \\
\hline 26 & 0.0004 & 0.0005 & 0.1012 & 0.2870 & 0.9990 & 1.0000 \\
\hline 27 & 0.0004 & 0.0006 & 0.1014 & 0.3499 & 0.9996 & 1.0000 \\
\hline 28 & 0.0004 & 0.0006 & 0.1015 & 0.4243 & 0.9998 & 1.0000 \\
\hline 29 & 0.0004 & 0.0006 & 0.1018 & 0.6163 & 0.9999 & 1.0000 \\
\hline 30 & 0.0004 & 0.0006 & 0.1020 & 0.6825 & 1.0000 & 1.0000 \\
\hline 31 & 0.0004 & 0.0007 & 0.1023 & 0.7464 & 1.0000 & 1.0000 \\
\hline 32 & 0.0005 & 0.0007 & 0.1026 & 0.8038 & 1.0000 & 1.0000 \\
\hline 33 & 0.0005 & 0.0007 & 0.1029 & 0.8525 & 1.0000 & 1.0000 \\
\hline 34 & 0.0005 & 0.1005 & 0.1033 & 0.8915 & 1.0000 & 1.0000 \\
\hline 35 & 0.0005 & 0.1005 & 0.1038 & 0.9217 & 1.0000 & 1.0000 \\
\hline 36 & 0.0005 & 0.1006 & 0.1043 & 0.9442 & 1.0000 & 1.0000 \\
\hline
\end{tabular}




\begin{tabular}{ccccccc}
\hline \multirow{2}{*}{ Height } & \multicolumn{5}{c}{ Aircraft Size } \\
\cline { 2 - 6 } (ft AGL) & F - 150g & E - 250g & D - 500g & C - 1.5kg & B - 3kg & A - 8kg \\
\hline 37 & 0.0005 & 0.1006 & 0.1048 & 0.9606 & 1.0000 & 1.0000 \\
\hline 38 & 0.0005 & 0.1006 & 0.1055 & 0.9723 & 1.0000 & 1.0000 \\
\hline 39 & 0.0005 & 0.1007 & 0.1062 & 0.9807 & 1.0000 & 1.0000 \\
\hline 40 & 0.0005 & 0.1007 & 0.1070 & 0.9865 & 1.0000 & 1.0000 \\
\hline 41 & 0.0006 & 0.1008 & 0.1079 & 0.9906 & 1.0000 & 1.0000 \\
\hline 42 & 0.0006 & 0.1008 & 0.1089 & 0.9935 & 1.0000 & 1.0000 \\
\hline 43 & 0.0006 & 0.1009 & 0.1101 & 0.9955 & 1.0000 & 1.0000 \\
\hline 44 & 0.0006 & 0.1009 & 0.1114 & 0.9969 & 1.0000 & 1.0000 \\
\hline 45 & 0.0006 & 0.1010 & 0.1129 & 0.9978 & 1.0000 & 1.0000 \\
\hline 46 & 0.0006 & 0.1010 & 0.1145 & 0.9985 & 1.0000 & 1.0000 \\
\hline 47 & 0.0006 & 0.1011 & 0.1164 & 0.9989 & 1.0000 & 1.0000 \\
\hline 48 & 0.0007 & 0.1011 & 0.1185 & 0.9993 & 1.0000 & 1.0000 \\
\hline 49 & 0.0007 & 0.1012 & 0.1208 & 0.9995 & 1.0000 & 1.0000 \\
\hline 50 & 0.0007 & 0.1013 & 0.1234 & 0.9996 & 1.0000 & 1.0000 \\
\hline 55 & 0.1005 & 0.1017 & 0.1419 & 0.9999 & 1.0000 & 1.0000 \\
\hline 60 & 0.1006 & 0.1022 & 0.1734 & 1.0000 & 1.0000 & 1.0000 \\
\hline 80 & 0.1011 & 0.1061 & 0.6322 & 1.0000 & 1.0000 & 1.0000 \\
\hline 85 & 0.1013 & 0.1078 & 0.7294 & 1.0000 & 1.0000 & 1.0000 \\
\hline 90 & 0.1015 & 0.1099 & 0.8143 & 1.0000 & 1.0000 & 1.0000 \\
\hline 95 & 0.1017 & 0.1124 & 0.8794 & 1.0000 & 1.0000 & 1.0000 \\
\hline 100 & 0.1020 & 0.1156 & 0.9245 & 1.0000 & 1.0000 & 1.0000 \\
\hline & & & & & \\
\hline
\end{tabular}

